\title{
La formación de las elites liberales en el México del siglo xix: Instituto de Ciencias y Artes del estado de Oaxaca*
}

\author{
Annick Lempérière \\ UNIVERSIDAD DE PARIS-I
}

\begin{abstract}
"En el gobierno republicano es donde se requiere de todo el poder de la educación."
\end{abstract}

Del espiritu de las leyes, iv, 5.

$\mathrm{E}$ 1 Instituto de Ciencias y Artes de Oaxaca fue una de las instituciones de enseñanza secundaria y superior que se crearon después de la independencia en las capitales de los estados de la república federal mexicana. ${ }^{1}$ De acuerdo con la perspecti-

* Traducción: Gabriela Montes de Oca Vega.

1 Sobre la historia de los institutos, todavía sumamente yerma, el estudio pionero es el de Herrejón Peredo, Fundación, 1978, cuyo principal mérito es haber subrayado el contexto cultural de la fundación del Instituto; en el mismo registro, véase Buchanan, Instituto, 1981; en conjunto, la historiografia mexicana relativa a los principales institutos sigue siendo más clásicamente institucional, véanse Castrejón Diez y M. Pérez Lizaur, Historia, 1976; García Luna, va que adoptaremos aquí, este Instituto reveló menos de la historia social que de la historia política y cultural. Mientras el análisis de las características sociológicas del alumnado sigue siendo dificil de realizar debido a las lagunas de las fuentes, ${ }^{2}$ el de las carre-

Instituto, 1986; García González, Conciencia, 1988; del mismo autor, Francisco, s.f.; sobre el Instituto de Guadalajara (1826) y sus equivocaciones, véanse Martínez Reding, Historia, 1981, vol, II, pp. 521 ss, vol. III, pp. 318 ss.; Ruz Menéndez, Historta, 1989; el Instituto de Oaxaca no ha sido objeto de estudios recientes, Berry le dedica algunas páginas en Reforma, 1898, pp. 28-31. Sobre los asuntos relacionados con la educación, en particular la superior, en el México del siglo xux, véanse Ensayos, 1985, en particu. lar Staples, "Panorama", 1985, pp. 127-144; Staples, Educar, 1985; Guerra, Mexique, 1985, vol. I, "Les mutations culturelles", pp. 341-403.

2 Las investigaciones en archivos se efectuaron en el transcurso de una estancia de dos meses en México, incluidas tres semanas en Oaxa- 
ras y la acción política de quienes surgieron de sus filas permite medir su importancia en la formación de una elite liberal culturalmente homogénea que moldearía la historia del estado de Oaxaca y que participaría en la de la república mexicana.

El término "formación" se entiende en el doble sentido de "creación" (o reproducción) de una elite social y política y de "preparación" intelectual y cultural. Mi hipótesis consiste en que, en ambos casos, el Instituto de Ciencias y Artes desempeñó una función primordial. Hasta la década de 1850 , formó y abrigó al grupo de los futuros dirigentes liberales. Cuando éstos aseguraron su poder, a escala regional y nacional, el Instituto se encontraba en

ca, en 1990. Las fuentes procedentes del Instituto o que se refieren a él se caracterizan por su discontinuidad. Los archivos del Instituto, asî como una parte de los correspondientes a la escuela primaria, asignados bajo la responsabilidad del Instituto entre 1860 y 1891 , se conservan en la Universidad Autónoma Benito Juárez de Oaxaca (Archivo uABjo); pudimos tener acceso a ellos gracias al apoyo de Francisco José Ruiz Cervantes, investigador del Instituto de Humanidades de la va Bio. Esos archivos presentan enormes lagunas; los documentos de los años de 1830-1860 fueron destruidos en gran parte. El Archivo General del Estado de Oaxaca (AGEO) conserva en la serie "Gobernación" elementos de la correspondencia entre el Instituto y el gobierno del estado (no clasificados); para los años de 1840, en la época del centralismo, el Archivo General de la Nación (AGN, México) conserva en la serie "Justicia e Instrucción Pública" la corres. pondencia con el gobierno de México. Estos tres fondos de archivos nos ofrecieron preciosos documentos, sobre todo listas de inscripción en diferentes periodos. Al parecer el Instituto no conformó nunca expedientes individuales sobre sus alumnos, de ahí la ignorancia sobre sus antecedentes familiares y sociales. Esta laguna se relaciona menos con la negligencia adminis- el centro del dispositivo de reproducción y de transmisión de sus valores. Como foco del partido liberal, el Instituto permite definir mejor al "liberalismon mexicano, en su variante oaxaqueña, como una cultura, un conjunto de convicciones y de prácticas que modelaron un medio social y sus formas de sociabilidad. La discontinuidad y el mal estado de las fuentes, así como las constantes manipulaciones que las autoridades hicieron de las cifras esco. lares y políticas en el siglo pasado, vuelven inútil todo intento de aproximación cuantitativa rigurosa. Por el contrario, el interés siempre renovado de los eruditos locales y de las autoridades encargadas de la institución por la evocación del éxito político y social de

trativa de los responsables del Instituto, o con el mal estado de las fuentes, que con lo reducido del grupo social del que reclutaba el Instituto a sus alumnos: no son en lo absoluto necesarios documentos de identificación en un medio donde todo el mundo se conoce, y la erudición local permitía, para los alumnos que alcanzaban celebridad, compensar en parte esta ignorancia. Los informes administrativos anuales de los gobernadores ante el Congreso, que se conservan tanto en el AGEO, como en la Biblioteca Nacional (BN, "Caja fuerte", Fondo reservado, México) completaron las fuentes de los archivos. Por lo que concierne a los impresos (discursos de otorgamiento de premios, "oraciones civicas"..., fuentes de primer plano para conocer la cultura liberal), el licenciado Luis Castañeda Guzmán, notario y notable de Oaxaca, antiguo alumno del Instituto antes de que éste se convirtiera en la universidad del estado, nos abrió generosamen. te su biblioteca personal y su colección de "folletería". La Colección Lafragua (BN, "Caja fuerte $^{n}$ ) así como la biblioteca condumex (México, Coyoacán) conservan igualmente numerosos folletos. Estas fuentes han sido complementadas con periódicos de Oaxaca que se conservan en la Hemeroteca Nacional (BN) y en la biblioteca del AGN. 
la elite formada en el Instituto, ofrece una de las claves que permiten comprender el lugar central que este Instituto ocupó en la historia regional.

La noción de cultura liberal, más bien que la de ideología, permite abordar el asunto del anclaje social del libe. ralismo. Las ideas liberales -mérito individual, progreso, libertad-que inspiraba la pedagogía oaxaqueña, coexistían con estructuras familiares y clientelistas particularmente influyentes que limitaban los fenómenos de movilidad social. ¿Cómo se articulaba la existencia del Instituto con la permanencia comprobada de parientes poderosos, que tendían a monopolizar las funciones de prestigio $y$ de poder en el estado? Ésas son algunas de las preguntas que se pretenden abordar aquí.

Fue doble la preocupación de quienes dirigieron la fundación y luego el desarrollo del Instituto. Es importante abordar su historia teniendo en mente esos dos objetivos declarados, de los cuales se verá que el primero se logró plenamente, mientras que el segundo no pudo realizarse.

El primero de los objetivos fue el de formar la elite política del estado de Oaxaca. En el desarrollo de la federalización de México (Constitución de 1824), la creación de los institutos en algunos de los estados más importantes de la nueva república, contribuyó a dar cuerpo a la autonomía de los poderes regionales, al permitir la formación en el propio lugar, de los magistrados necesarios para las nuevas instituciones políticas locales. Procurar la obtención de un diploma en dichos institutos constituía, paralela- mente a la vida militar, el camino civil de acceso al poder.

En Oaxaca se aprecia también claramente el papel que desempeñaron esos establecimientos en la forma. ción de facciones políticas. Durante los 20 años siguientes a su creación en 1826 , fue en el Instituto donde tomó cuerpo el núcleo del futuro partido liberal oaxaqueño, cuya aportación sería esencial para el movimiento liberal que emprendió la conquista del poder nacional en el decenio de 1850. El estado de Oaxaca tuvo, hasta Ia revolución, una importancia política que la pobreza y la marginalidad que hoy lo caracterizan no permiten ya apreciar. Dos de los más grandes estadistas del siglo, Benito Juárez (jefe de los liberales y vencedor político de los conservadores, presidente de México de 1858 a 1872) y Porfirio Díaz (uno de los héroes militares de la guerra contra las fuerzas imperiales de Maximiliano, presidente de la república constantemente reelegido entre 1876 y $1910^{3}$ y fundador de un régimen político autoritario y "estable" [un liberalismo positivista de corte anglosajón] bautizado como "porfiriato") nacieron ahí, realizaron sus estudios en el Instituto de Cien. cias y Artes y comenzaron su carrera política en su estado natal, donde reclutaron una cohorte de fieles que los acompañaron y sirvieron en la conquista del poder federal. Que el Instituto, en el plano político, haya respondido a los deseos de la elite liberal oaxaqueña se manifiesta en el orgullo que tantas veces pregonaban

${ }^{3}$ Salvo entre 1880 y 1884. 


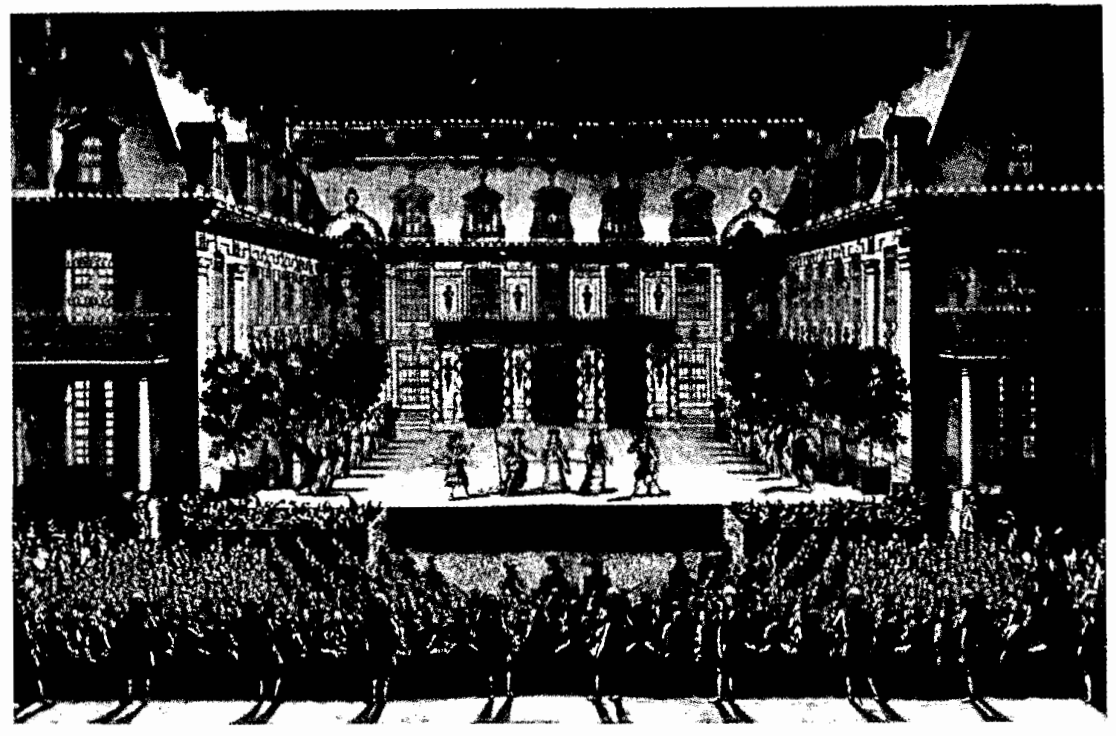

sus voceros: "Oaxaca, baluarte inexpugnable de las libertades públicas, tiene la gloria envidiable de ser la cuna del primer americano de este siglo, de Benito Juárez, el defensor de la integridad de América y el vencedor de la ignorancia y el clericalismo..."4 Se abordaba así el dominio de la historia cultural, puesto que el Instituto de Oaxaca se convirtió en el crisol donde se elaboraría, se conservaria y se transmitiría el ideal liberal [latino]. Este ideal, uno de cuyos fundamentos filosóficos era la creencia en la perfectibilidad del hombre y de la sociedad, puso en el primer

4 Sigue la enumeración de los grandes hombres que, habiendo nacido y sido educados en el estado, conocieron un destino de carácter nacional, Velasco, Geografia, 1891, pp. 12-13. plano de las preocupaciones la educación de las elites, por la que se esperaba formar a los ciudadanos modelo encargados de mostrar a toda la sociedad el ejemplo de la responsabilidad individual y de la voluntad de progreso.

Así se llegaría al segundo objetivo del Instituto: preparar a quienes serian los agentes del "progreso" del estado de Oaxaca en el conjunto nacional. Compartido por todos los liberales, este objetivo de "progreso" se inscribía en un contexto regional cuyos aspectos generales conviene señalar. La antigua intendencia de Oaxaca, situada al sur del virreinato de Nueva España, encontraba en la época colonial su principal fuente de prosperidad en la producción y comercialización de la 
cochinilla. Esta actividad entró en decadencia después de la independencia, ${ }^{5}$ lo que redujo los recursos fiscales del gobierno del estado "libre y soberano", miembro de la República federal de México, constituida en 1825. Pero su peso demográfico compensaría su relativo retroceso económico. Con una población de más de 400000 habitantes en los años de 1820, que alcan. zaría el millón en vísperas de la revolución de 1910,6 el estado de Oaxaca disponía de un recurso indispensable en el siglo XIX para influir sobre los destinos de la nación: el de las armas.

Los indígenas, que representaban las dos terceras partes de la población, constituían la segunda particularidad del estado. Se dividían en dos etnias principales, la de los zapotecos y la de los mixtecos, de donde provenían, respectivamente, Juárez y Díaz (mestizo, este último). Los indígenas eran el contingente mayor de las fuerzas armadas en las guerras civiles, así como los contribuyentes más numerosos. En el siglo XIX, su peso demográfico y la vitalidad de sus tradiciones comunitarias les permitieron, a diferencia de sus congéneres de otras regiones, conservar en su poder alrededor de $50 \%$ de las tierras agrícolas del estado. El resto se dividía entre explotaciones agrícolas con mano de obra indígena, grandes haciendas y ranchos de tamaño más modesto. La historia agraria del estado en el siglo XIX se compondría fundamentalmente de los conflictos que en-

5 Véanse Hamnett, Política, 1976, y “Comercio, 1990 , pp. $345 \cdot 366$.

6 Carriedo, Estudtos, 1949; Chassen, "Pre-

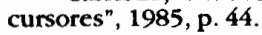

frentaron a comunidades y hacendados por la conservación o la ampliación de sus respectivas tierras. ${ }^{7}$

La presencia de una población indi. gena tan numerosa constituyó un gran desafio para las autoridades que, al mismotiempoque estaban constantemente preocupadas por elevar el nivel cultural y económico de su estado, con demasiada frecuencia se mostraban convencidas de la incapacidad para el "progreso" de las poblaciones indígenas:

La mayor parte de los habitantes, desparramados en miserables aldeas y en su gran extensión sin conocer muchos ni el idioma común, sabe que pertenece a esta sociedad porque se le cobra el impuesto o los derechos parroquiales, porque ha sido designado para el servicio militar o porque ha caído en manos de autoridad para el castigo de alguna falta; nada de educación civil ni religiosa, ningún goce, ninguno de los bienes y adelantos de los pueblos civilizados. ${ }^{8}$

La resistencia pasiva que en la generalidad de los casos opusieron los al-

7 Véase Taylor, Landlord, 1972, Historia, vol. I, Prehtspantco 1924, 1988; Lecturas, 1990, vol. III, pp. 343-434.

8 [Dublán], Memoria, 1863, pp. 4-5. Como lo escribe sin ambajes $M$. Brioso y Candiani, historiador de su estado natal y heredero de la tradición liberal, "esas masas habrían de ser un obstáculo para la total civilización del pueblo de Oaxaca, en razón de su miseria económica y del débil desarrollo de sus facultades intelectuales y morales". Evolución, 1941, p. 6. Los seminarios, así como los colegios abiertos por ciertas órdenes religosas (principalmente jesuitas hasta 1767, pero también franciscanos, etc.) constituían en la época colonial los centros de ense. ñanza secundaria; en 1810 exiśran igualmente en México dos universidades, la de México, fundada en 1552, y la de Guadalajara, abierta en 1791. 
deanos a la política escolar de las autoridades sólo se equipara con la obstinación con que se les quiso transformar, en contra de su voluntad y mediante la escuela primaria, en ciudadanos ilustrados y en productores educados.

En ese telón de fondo étnico de singular presencia, las esperanzas basadas en el Instituto y en quienes habían salido de él para conducir al estado de Oaxaca por la vía de la modernidad correspondían pues, al deseo de que el estado siguiera contando en la historia nacional. Sin embargo, mientras las regiones pioneras del norte de México, marginadas durante mucho tiempo, conocian a fines del siglo XIX un desarrollo económico y demográfico acelerado que las preparaba para cumplir un papel motor en el México revolucionario, la tendencia del estado al declive por el retroceso relativo de su peso económico terminaría por imponerse, y en el momento mismo en que el Instituto y las elites oaxaqueñas parecían gozar de un apego político y cultural. Este hecho ilumina con una luz particular los esfuerzos que duran. te un siglo realizó Oaxaca para modernizarse mediante la educación.

\section{LA FUNDACIÓN DEL INSTITUTO: EL. CONSENSO ILUSTRADO}

Inaugurado el 8 de enero de 1827 , el Instituto de Ciencias y Artes de Oaxaca fue creado en virtud de la ley de instrucción pública que aprobó por votación el 26 de agosto de 1826 la Cámara Legislativa local, compuesta de quince diputados. Nuestra primera tarea será la de revisar la historia de los inicios del
Instituto. En efecto, sus antiguos alumnos y sus directores no cesaron, hasta la mitad del siglo XIX de escribir la historia de la institución más prestigiosa del estado, pero con un enfoque poco satisfactorio para el historiador de hoy. Se trata, sobre todo, de precisar el carácter de las relaciones que estableció esta nueva institución, donde se prescribía la enseñanza en lengua vulgar y se crearon, al compás de las reformas educativas emanadas de la revolución francesa, cursos de ciencias y humanidades junto a los impartidos por las instituciones eclesiásticas. Tanto los liberales de mediados del siglo pasado como los directores positivistas de la institución de inicios de este siglo, presentaron la creación del Instituto como fruto de una voluntad de enfrentarse a la Iglesia y el Seminario, que detentaban entonces el monopolio de la enseñanza secundaria y superior. El Instituto era un establecimiento de enseñanza pública que proporcionaba una formación científica y humanista y fue creado por un congreso local donde la mitad de los diputados eran eclesiásticos, ${ }^{9}$ abiertos a las ciencias y a las humanidades.

En 1826, la vida política del estado, dotado de una Constitución en 1825, estaba marcada por el consenso. Los textos y los hechos de la época no muestran sino la preocupación por formar una elite educada y más precisamente, el futuro personal político y administrativo del estado. El gobernador Morales, después de recordar los servicios prestados por el Seminario, dice del Instituto en 1827 :

\footnotetext{
9 Brioso y Candiani, Evolución, 1941, p. 29.
} 
Este establecimiento es muy útil; y debería causar sin duda alguna ventajas bien considerables al estado, por haber en él varias cátedras que no se hallan establecidas en el colegio Seminario. ${ }^{10}$

Las memorias de Benito Juárez, aunque sumamente teñidas de anticlericalismo, confirman las palabras del gobernador:

No había más establecimiento literario que el colegio seminario conciliar, en que se enseñaba únicamente gramática latina, filosofia, fisica elemental y teología, de manera que, para seguir otra carrera que no fuese la eclesiástica o para perfeccionarse en algún arte $u$ oficio, era preciso poseer un caudal suficiente para ir a la capital de la nación o a algún país extranjero, para instruirse o perfeccionarse en la ciencia o arte o el oficio a que uno quisiera dedicarse. Para los pobres como yo, era perdida toda esperanza. ${ }^{11}$

La creación del Instituto tenía pues todo que ver con los nuevos tiempos y la adopción del sistema federalista, que hizo necesario formar en el lugar a la futura elite del "estado libre y soberano". En la Oaxaca colonial, donde no existía más que el Seminario fundado en el siglo XVII, no se disponía de formación en derecho civil ni en medicina. En su informe al Congreso en 1831, el gobernador insistía en la utilidad inmediata del Instituto, que sin embargo conocería inicios dificiles:

Pero un estado libre, soberano e independiente en su administración inte-

${ }^{10}$ Morales, Memoria, 1827, p. 23

11 Juárez, Apuntes, 1976, p. 10 , rior, que nombra representantes para el congreso federal, que tiene un cuerpo legislativo, un gobierno supremo, tribunales de justicia y funcionarios subalter. nos de esos poderes, y que se renuevan a los $2,3,4$ y 5 años de servicio, necesita de ciudadanos de ilustración, de conocimientos y virtudes, $y$ por consiguiente de que una general instrucción forme esa porción de hombres útiles que ha. gan el bien de la comunidad. 12

Lejos de intentar competir con el Seminario, el Instituto debía complementarlo incorporando nuevas materias a la enseñanza: lenguas vivas, ciencias naturales, economía política, etcétera.

Así pues, el voto de la ley de 1826 por los diputados eclesiásticos no es parađójico más que en apariencia. Va a la par con la presencia de varios clérigos entre los primeros profesores de la institución. Hombres de iglesia y laicos no sólo participarian conjuntamente en la fundación institucional del Estado, sino que compartirían la misma cultura política, la de un "protoliberalismo" mexicano cuyo apogeo y resultados pueden verse en ese momento privilegiado. Desde los inicios del proceso de independencia (1808), las "Luces", para hablar con el lenguaje de las elites de la época, se expandieron en los medios letrados y la libertad de pensamiento y de prensa, al paso del debilitamiento del "despotismo ilustrado" practicado por los Borbones durante la segunda mitad del siglo XVIII.

Virtud, Libertad, Saber, tales eran los bienes, patrimonio de las repúbli-

${ }^{12}$ Exposicion, 1831, p. 12. 
cas, de los que se estaba convencido de poder gozar sin trabas, al liberarse de la "arbitrariedad" y el absolutismo, y son los que se intentará propagar mediante la educación. En el discurso que pronunció en ocasión de la inauguración del Instituto, José Juan Canseco, senador, eclesiástico y "licenciado", asoció el suceso con el fin del "despotismo" y de la "tiranía", con la "Libertad" consagrada por el "pacto general" $^{n}$ es decir, la creación de la federación formada por "Estados independientes y federados del septentrión": "Sin la libertad, no se habría emprendido, ni la libertad misma sería duradera sin la realización de la empresa." Considerada a la vez como un "derecho natural" y una "virtud cívica" que debía inculcarse y preservar del "libertinaje" y de la "anarquía", la libertad debía, según Canseco, encontrar en el Instituto su más firme apoyo. Los cursos de derecho enseñarían a la juventud oaxaqueña que la Libertad "perfecciona la especie humana y adelanta el arte social hacia la felicidad de los pueblos, mejorando la legislación y destruyendo las preocupaciones adversativas a la condición de los seres inteligentes." 13

La florida retórica de Canseco se alimentaba de innumerables referencias a una cultura común que asociaba los ejemplos de la virtud republicana, elegidos en la historia griega y romana, con los grandes textos del pensamiento político de las Luces y de la modernidad surgida de la revolución france-

13 "Discurso del C. J. Canseco en la Inauguración del Instituto" [1827], en Instituto, 1990, pp. $7 \cdot 15$. sa, desde Filangeri hasta Bentham. Las compras de libros efectuadas por el Instituto desde $1827,{ }^{14}$ así como las listas de las obras que le obsequiaron los notables, ${ }^{15}$ confirman el vigor de esta cultura común heredada de la Ilustra. ción, así como su coexistencia con un saber tradicional de esencia religiosa. Las compilaciones de derecho canónico y las obras de teología asocian a sus donadores con Montesquieu, Rousseau, Condorcet, Benjamin Constant y Destutt de Tracy. De la lectura de esos libros, los oaxaqueños parecen haber extraído, sobre todo, una fe ilimitada en la eficacia de las buenas leyes y de las constituciones para crear desde la nada una sociedad a la vez virtuosa y dirigida hacia el progreso, a pesar de los temores que inspiraba, desde esas fechas la situación de los "pueblos in dígenas".

La formación laica impartida por el Instituto no impedía de ningún modo que fuera gobernado por eclesiásticos ni que su disciplina fuera muy similar a la del Seminario. ${ }^{16}$ Esta etapa que los historiadores positivistas han llamado el periodo "teológico" del Instituto, ${ }^{17}$

14 "Libros comprados por la Junta Directora del Instituto de Ciencias y Artes del Estado de Oaxaca", AGEO, Gobernación: 1827.

15 "Donaciones a la biblioteca del Instituto...", Cartas al pueblo, núm. 12, sábado 10 de febrero de 1827, p. 1, núms. siguientes (Hemeroteca Nacional, BN).

${ }^{16}$ Martínez Gracida, "Reseña", reconoce que la vida en el Instituto en los primeros años se parecía mucho más a la de una institución religiosa.

17 "El Instituto conoció un periodo teológico prolongado de veinte años, durante el cual fue sucesivamente dirigido por tres eminentes eclesiásticos", Pardo (varias veces director del Instituto entre 1908 y 1921), Breve, 1926, p. 6. 
que se prolongó mucho tiempo después de desencadenarse los conflictos políticos entre "liberales" $y$ "conservadores" ${ }^{n}$, nutridos por la cuestión del lugar que ocuparía la Iglesia en una sociedad republicana.

Sin embargo, desde el inicio, hubo una especificidad del Instituto, una actitud mental, una enseñanza y un alumnado que lo diferenciaban del seminario. Establecimiento público gratuito, el Instituto dio a conocer su programa de trabajo y se declaró abierto "a todo el mundo, para que cualquiera sin distinción de clase, de condición, ni ropaje [...]." ${ }^{18}$ En todos esos primeros años, atrajo alumnos y maestros que, tras entrar primero en el Seminario sin vocación, se incorporaron a los estudios de derecho: es el caso de Miguel Méndez, inscrito desde 1827 , quien convenció a su congénere zapoteco Benito Juárez, nacido como él en la sierra, de inscribirse en 1829; Marco Pérez, indígena también pero cuyos antecedentes no se conocen bien, enseñó ahí algunos años más tarde. ${ }^{19}$ Mientras los hijos de los notables ponían mala cara a la institución en sus primeros años, ésta atraía a los jóvenes que veían en ella su única oportunidad de ascenso social. Con razón: Juárez, huérfano de una pareja de campesinos zapotecos, ingresó al Instituto en 1829, figuró en 1831 como regidor del Ayuntamiento, obtuvo el título de abogado en 1834, y

18 "La Junta Directora del In: "ituto...", carta manuscrita de Flores Márquez, secretario, 10 de enero de 1827, AGEO, Gobernación: 1827.

${ }^{19}$ Sobre los miembros del grupo liberal, hay numerosos datos biográficos en Iturribarría, $G e$ neracion, s.f.; Ramírez, Hombres, 1948; Martínez Gracida, Efemérides, 1892. fue nombrado juez; enseñó física y derecho canónico en el Instituto y habría de ser su director en 1852, después de haber sido gobernador del estado. ${ }^{20}$ Durante todos esos años, Juárez también se dedicó activamente a la formación de la facción liberal oaxaqueña.

\section{EL INSTTTUTO, CUNA DEL PARTIDO LIBERAL Y SANTUARIO DE LA CUITURA LIBERAL OAXAQUEÑa}

El historiador Ch. Berry escribió justamente que el Instituto fue "el Alma Mater de buen número de dirigentes nacionales del partido liberal" ${ }^{21}$ Juárez, como gobernador, no decía otra cosa en 1852: "La mayor parte de los hombres ilustrados que ocupan los destinos del estado ha salido de ese benéfico establecimiento." ${ }^{22}$ Nuestra intención no es seguir la historia de la conquista del poder local, y luego del nacional, por parte de los liberales oaxaqueños, sino mostrar cómo el Instituto se encontraba en el centro del proceso de formación de una facción política, la de los liberales, durante el periodo de incertidumbre e inestabilidad política que comenzó a fines de los años de 1820. Tradicionalmente se afirma que los primeros liberales se agruparon en 1829 alrededor de Miguel Méndez, joven profesor del Instituto muerto prematuramente en 1830 , orador inflamado y maestro de los "principios y autores liberales" en su curso de lógica. ${ }^{23}$ De este episodio

\footnotetext{
20 Véase Juárez, Documentos, 1972.

21 Berry, "Ficción", 1990, p.335.

22 Juárez, Exposición, 1852, p. 20.

23 Martínez Gracida, "Reseña", s.f.
} 
no comprobado y casi mítico se pueden retener, como elementos de verdad, para la conformación del partido liberal, la fuerza de los vínculos crea. dos en el seno del Instituto entre alumnos y profesores, $\tan$ poco numerosos al inicio y unidos por el rechazo común a los estudios eclesiásticos y la importancia del verbo vía la enseñanza del arte oratorio en la propagación del ideal liberal.

Mientras el "protoliberalismo" evocado anteriormente declinó con la aparición de los primeros conflictos políticos violentos a fines de $1820,{ }^{24} \mathrm{se}$ afirmaba un ideal conservador que reunía a quienes deseaban mantener el cuadro jurídico del antiguo régimen y que eran partidarios de un poder cen. tral fuerte. En el bando conservador que dominó Oaxaca hasta finales de 1840 , se encontraba la lglesia (pero no todos los clérigos), el ejército profesional (pero no todos los militares) y la mayor parte de los grupos sociales cuyos intereses económicos se vinculaban a las estructuras coloniales (comerciantes y hacendados, aunque algunos de éstos habrian de ser liberales). Es una forma de decir que la facción liberal reagrupó, alrededor de miembros de las elites antiguas, eclesiásticas y de familias de grandes hacendados como los Mimiaga, los Arteaga, los Esperón José Esperón sería uno de los hombres fuertes de la facción liberal local hasta los años de 1870 ), notabilidades recientes como el médico Bolaños u hombres nuevos como Juárez o Marcos Pérez quienes debieron su ascensión social y su as-

24 Véase Costeloe, Primera, 1975. cendiente moral a sus estudios en el Instituto.

Con Miguel Méndez, los primeros profesores, los licenciados Francisco Banuet, Francisco Mimiaga, José Simeón Arteaga, el médico Juan Nepomuceno Bolaños y, en los años siguientes, Lope San Germán, Marcos Pérez, José María Núñez, el propio Juárez, serán los voceros de un liberalismo más radical, favorable a reformas inmediatas. Nacidos todos antes de 1810 (Pérezy Méndez nacieron en 1805, Juárez en 1806), constituyeron la primera generación liberal posindependentista, la que ingresó a la política en los años de 1830 y comenzó a ocupar el gobierno local a mediados de la década siguiente, cuando se desmoronó el po. der del hombre fuerte de la región, Antonio de León, a quien habían apoyado los conservadores.

Estos liberales de la primera generación, que sumaban a su magisterio en el Instituto, la acción política, y algunos de ellos su pertenencia a la masonería, ${ }^{25}$ fueron los formadores intelectuales y los patronos políticos de dos grupos de la generación liberal siguiente, la de la Reforma (1855) y la de la guerra de Intervención (1863-1867): una generación intermedia de hombres nacidos alrededor de 1815-1820, y la generación de Porfirio Díaz, nacida alrededor de 1830 , cuyos miembros a menudo empezaron por ser juaristas antes de adhe-

${ }^{25}$ Es sobre todo el caso de Francisco Banuet, quien parece haber iniciado a Juárez, véase $\mathrm{Ma}$ teos, Historia, 1884, p. 91; "Acta de iniciación masónica de Juárez, en la ciudad de México", 15 de enero de 1847, en Juárez, Documentos, 1972, vol. I, pp. 422-423. 


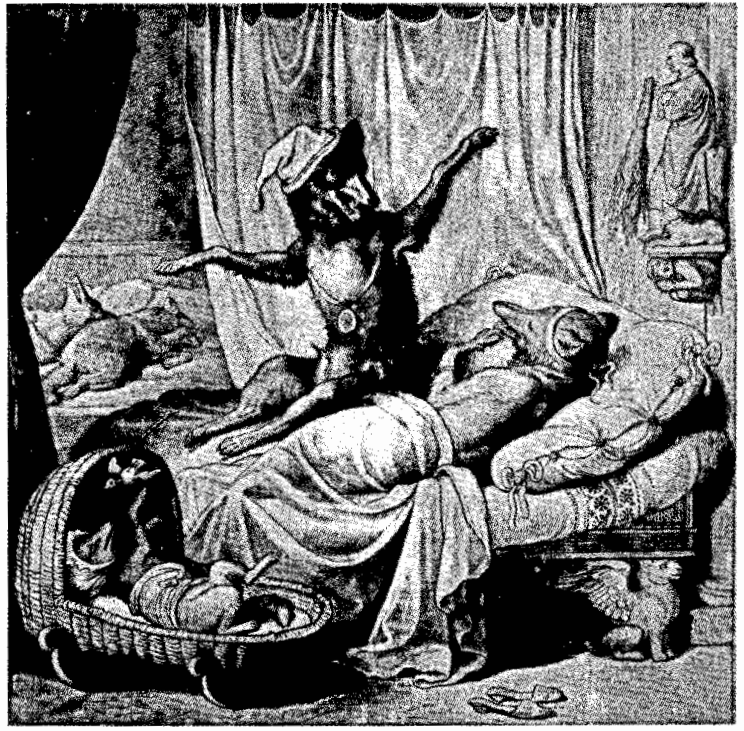

rirse, entre 1870 y 1876 , a la persona de Díaz.

Una de las aportaciones del Instituto a la constitución de la elite liberal, poco subrayada por los historiadores, reside en el hecho de haber formado los hombres a quienes un historiador oaxaqueño llamó felizmente "oficiales licenciados" o "mílites profesionistas". ${ }^{26} \mathrm{Si}$ bien no todos esos oficiales buscaron el título de abogado, por lo menos siguieron estudios de derecho en el Instituto, antes de elegir la carrera militar o de ser llevados a ésta por las circunstancias. Como miembros de la generación intermedia y de la generación porfirista, se distinguieron por su lealtad con respecto de los liberales civiles que

${ }^{26}$ Iturribaría, Díaz Ordaz, 1967, p. 67. ocuparon el poder a partir de finales de los años de 1840. Tras haber ingresado ya fuese al ejército regular, $o$ bien a las milicias que participaban en las guerras civiles en épocas de problemas, todos se incorporaron a la Guardia Nacional creada por Juárez, durante su primer mandato como gobernador (18471852), para oponerse a la indisciplina de los militares de carrera, conservadores: ${ }^{27}$ tal es el caso de Ignacio Mejía, ${ }^{28}$ Ramón Cajiga, José María Díaz Ordaz o de José María Ballesteros. ${ }^{29}$ Cuando

27 Juárez, Exposición, 1849, p. 4.

28 Muñoz y Pérez, Mejía, 1966.

29 Resumen biográfico en "Las logias simbólicas de esta ciudad celebraron hoy en sesión pública, con severa y majestuosa solemnidad, las honras fúnebres del Sr. Lic. general José María Ballesteros", Pertódico Oficial del Gobierno del Estado de Oa$x a c a$, núm. 8, 27 de enero de 1882, p. 2. 
ocupó su segundo mandato como gobernador en 1856-57, Juárez disolvió el ejército regular y no dejó que subsistiese más que la Guardia Nacional, incorporándole a todos los militares que le eran fieles. La asociación entre civiles y militares formados en el mismo crisol cultural constituye una de las características originales del liberalismo oaxaqueño, si no es que del liberalismo mexicano en su conjunto. ${ }^{30}$ Uno de aquellos "oficiales juaristas" no era otro que Porfirio Díaz, quien terminó sus estudios de derecho en el Instituto en 1854, llevando a cabo su práctica jurídica bajo la dirección de Marcos Pérez, al tiempo que cumplía las funciones de bibliotecario y de profesor interino de derecho natural. Los acontecimientos políticos le impidieron obtener el título de abogado, pues se alistó en la milicia liberal que combatió en el ejército profesional que sostuvo a Santa Anna, en 1854.31 Fue el inicio de una brillante carrera militar; su formación inicial era claramente la de un liberal oaxaqueño que estaba al servicio de Juárez durante la ocupación francesa, y que se cubrió de gloria en los combates contra las fuerzas imperiales. A partir de 1870, realizó carrera personal en el estado y, a la desaparición de Juárez en 1872 , reunió a su alrededor a varios liberales de su generación anteriormente juaristas.

La primera generación liberal tomó la sucesión del canónigo Cantarines en la dirección del Instituto en 1847 y la conservó hasta 1860. Durante esos años Bolaños, Juárez, Pérez y Lope San

30 Juárez, Exposición, 1849.

${ }^{31}$ Díaz, Memorlas, 1947, vol. I, pp. 38 ss.
Germán, se alternaron a la cabeza de la institución. ${ }^{32}$ Paralelamente, la facción liberal conquistaba el poder local. En 1845, Juárez se convirtió en el secretario de Gobierno del viejo caudillo Antonio León, uno de sus últimos pasos hacia el puesto de gobernador. En 1848 , aprovechando los problemas que siguieron a la derrota mexicana frente a los estadunidenses, la facción liberal se adueñó de la totalidad del poder local, un poder aún frágil que sus notables confiaron a Juárez. Después de su exilio forzado durante la dictadura del general Santa Anna, testaferro de los conservadores y de los centralistas, los liberales regresaron con fuerza gracias a la revolución de Ayutla (1855). Muchos oaxaqueños, entre ellos Juárez, fueron entonces llamados a cumplir funciones en el gobierno de México. A partir de la Reforma y hasta la llegada al poder de Díaz, los liberales controlarían las elecciones y ocuparían la totalidad de los puestos políticos y judiciales del estado de Oaxaca. 33

En 1860, la llegada de Manuel Dublán a la cabeza del Instituto marcó el paso a la generación liberal intermedia. Desde 1867 Félix Romero, uno de los más brillantes representantes de la generación porfirista y del liberalismo oaxaqueño, tomó el relevo. No fue sino hasta fines de los años de 1880 , con Aureliano Valdivieso (quien había ingresado como alumno del Instituto en 1867 y había sido nombrado director

32 Silva y Escobar, Instituto, 1952, p. 29.

33 Véase por ejemplo los resultados electora. les en La Victoria, vol. iv, núm. 2, jueves 9 de julio de 1863 y números siguientes (AGEO). 
por primera vez en 1889), cuando desaparecieron los liberales "históricos" para dar paso a una nueva generación de porfiristas positivistas, quienes, nacidos a mediados de siglo, no habían conocido más que la fidelidad personal a Porfirio Díaz.

A diferencia del "protoliberalismo" evocado en la primera parte de este trabajo, que se daba por satisfecho al haber puesto término a la dominación española y haber instaurado la "libertad", el liberalismo de la generación de Juárez y subsiguientes puede verse como una ideología de combate contra la sociedad del antiguo régimen hereda. da de la época colonial. Los liberales oaxaqueños, como sus homólogos de otras regiones de México, se oponían a la conservación de los privilegios y de la riqueza territorial de la Iglesia, deseban terminar con las corporaciones y sus bienes (de las hermandades pero también de las comunidades indígenas, con sus tierras colectivas), querían modernizar el estatuto del ejército para colocarlo al servicio de la república. Mientras los conservadores se apoyaban en los centralistas que querían un poder fuerte para luchar contra las fuerzas provincianas centrifugas, los liberales eran federalistas. ${ }^{34}$ En 1847 , Juárez y otros miembros de la facción liberal oaxaqueña formaban parte de los diputados al Congreso nacional

${ }^{34}$ En un documento impreso de 1835 , firmado, los liberales oaxaqueños piden al general Santa Anna, presidente de la República, que no sea abolida la constitución federalista de 1824: Representactón, 1835. El centenar de signata. rios constituye una buena fotografia de la facción liberal de Oaxaca hacia la mitad de los años de 1830. que habían votado a favor de la venta de bienes de la Iglesia para financiar la defensa contra la intervención norteamericana. Una vez nombrado gobernador de Oaxaca, Juárez adoptó algunas medidas de laicización (en particular la prohibición de sepultar dentro de las iglesias). Sin entrar en detalle sobre las luchas que continuaban animando la vida política local después del triunfo de la Reforma, se indicará solamente que los liberales - la generación de Juárez y las siguientes- se dividieron después de la promulgación de la Constitución en 1857, en "rojos" partidarios de reformas radicales, sobre todo contra la Iglesia, y moderados (llamados "borlados") que deseaban contemporizar con la Iglesia e insistir en la privatización de los bienes de las aldeas indígenas. ${ }^{35}$ Algunos letrados, fervientes liberales, como Bernardino de Carbajal, condiscípulo de Juárez en el Seminario, antes de seguirlo al Instituto y de hacer ahí toda su carrera como profesor, adquirieron los bienes de los conventos puestos a la venta a partir de $1857,{ }^{36}$ pero otros retrocedieron ante las medidas más anticlericales de la Reforma.

Sin embargo, esta visión exclusivamente ideológica y política del liberalismo se corresponde sólo a medias con la realidad. El tono de los discursos del gobernador Juárez, en el periodo anterior a la aplicación de la legislación radical de la Reforma, era mucho más moderado de lo que podrían dar a

35 Sobre la apropiación de tierras comunales por la familia de Esperón, véase Monaghan, "Desamortización", 1992, pp. 343-386.

${ }^{36}$ Berry, "Ficción", 1990, pp. 335-336. 
entender las memorias redactadas por el líder liberal hacia el final de su vida. Poner énfasis en las divisiones de los liberales encubre la pertenencia de sus miembros a una misma formación cívica cuyo principal centro era el Instituto. Esta formación se manifestaba en la organización de los exámenes y de los discursos de distribución de premios, en las ceremonias que marcaban su vida oficial y durante las cuales los profesores o los alumnos adelantados del Instituto eran designados como oradores. La transmisión de los valores liberales, que formaba parte explícitamente de las tareas del Instituto, inspiraba la pedagogía de la institución; ahí se formaban ciudadanos para el debate y las responsabilidades públicas, además de nutrirlos culturalmente.

El liberalismo oaxaqueño de la generación de Juárez compartía con el de los años de 1810 a 1830 dos rasgos paradójica pero estrechamente imbricados. El primero es el de su vínculo con la religión y la institución religiosa, el segundo, su relación con la Ilustración. El letrado liberal Carbajal, encargado en 1847 de bendecir la bandera de un batallón en pie de guerra, evocaba "la religión de nuestros padres, cuya suerte se ha identificado con la de la independencia y de la nación", y para él no existía ninguna contradicción aparente entre la evocación de los valores religiosos que debían guiar la acción del soldado, y la cita de reflexiones del barón de Holbach sobre la necesaria instrucción de los milita. res. ${ }^{37}$ No hubo ningún discurso liberal, incluidos los del gobernador Juá-

${ }^{37}$ Carbajal, Dtscurso, 1848. rez ante el Congreso local, que no invocase al "todopoderoso" 38 ni mencionase la importancia de la religión en la preservación del vínculo social, delorden público y de la identidad colectiva. En un discurso de distribución de premios que es un verdadero himno a la ciencia y al espíritu de descubrimiento, Juan Nepomuceno Bolaños, liberal y médico, entonces director del Instituto, llamaba a los alumnos a la humildad, citando: "aquel viejo romano memorable por sus cartas llenas de unción y de elocuencia [San Pablo]" ${ }^{39}$ A la inversa, persistía en cuantos se alejaban del nuevo liberalismo en nombre de los "privilegios" de la religión y de la Iglesia, una misma defensa de los valores de la Ilustración. Canseco, el senador que había inaugurado el Instituto, al disertar contra el establecimiento de la libertad de culto, citaba en apoyo de su tesis a los mismos autores que en 1827: no a teólogos ni a canonistas, sino a Filangieri, Bentham, Montesquieu. ${ }^{40}$ En el Seminario, el doctor (en teología) José Mariano Galíndez se mostraba ante los alumnos de artes como el apologista de la unión de la filosofía y de la religión, condenando de paso el fanatismo y la Inquisición y definía al buen ciudadano como a un servidor de la patria a un tiempo cristiano y educado. ${ }^{41}$ Puede ser divertido constatar que la mayoría de los profe-

38 "Si Dios nos sigue favoreciendo con la paz [...] Demos gracias al Todopoderoso que nos ha concedido el beneficio...", Juárez, Expasici6n..., 1849, pp. 3 y 4.

39 Bolaños, Discurso, 1850, p. 6 (BN, México, R 708 LAF).

${ }^{40}$ Canseco, Explicacion, 1849.

41 Galindez, Discurso, 1846. 
sores del Seminario, reabierto después de la Reforma al inicio de los años de 1870, llevaban los mismos patronimicos que los del Instituto, y que los programas que seguían y los manuales que empleaban eran idénticos casi en todos los puntos a los de la institución pública. Sobre el tema de la formación de ciudadanos confluyen los dos libera. lismos, y en ese punto el segundo no es más que la prolongación del primero.

No obstante, los estudios y la organización de la vida escolar propuestos por el Instituto introdujeron una ruptura en la jerarquía de las referencias culturales y en su presentación retórica. Si en los años de 1820 , los ejemplos de la antigüedad clásica y las citas latinas, bíblicas o no, florecian en los discursos públicos, desaparecieron progresivamente y se impuso, alrededor de 1840 y al lado de la retórica tradicional siempre viva de los sermones y discursos del ceremonial eclesiástico, un arte oratorio cuya forma y referentes humanistas habían mudado. Un lugar común entre los oradores de esa época que, a fin de cuentas, tomaron de los debates del siglo de las Luces, fue precisamente el rechazo proclamado de la "retórica vana" y la doble preocupación de mostrar "verdad y sencillez". Bolaños introdujo esta ruptura en su discurso de distribución de premios de 1851:

Algún antiguo griego [...] lo habria dicho con elocuencia, con bellezas oratorias, no hay que dudarlo; pero no con más acierto que yo, en cuanto al objeto del culto. La mitología ha perdido en esta parte sus prestigios; y a pesar de que pudieran inmortalizarla los poemas de Homero, de Virgilio, las obras de Só- focles y las de Ovidio, las creencias y las expresiones de homenaje tributadas en otros tiempos a aquella absurda mezcla de falsas deidades han desaparecido como la sombra, quitado el cuerpo que la formaba. 42

Los estudios impartidos en el Instituto, recordémoslo, en lengua vulgar, no incluían más que dos años de latín. Con la cultura clásica desapareció el estilo de oratoria que se adquiría al mismo tiempo que ella en el Seminario. Los historiadores que han subrayado, no sin razón, el tradicionalismo de los manuales utilizados durante mucho tiempo después de la independencia en las instituciones secundarias laicas, 43 no han destacado esta modificación decisiva de la cultura letrada introducida por el retroceso del latín y la expansión de los estudios científicos y humanistas.

La nueva cultura eliminó el arte de la oratoria. Por el contrario, los reglamentos del Instituto, a partir de la gran ley de reorganización de los estudios de 1845, promoverían una iniciación de los alumnos en los debates y en los discursos públicos, así como la adquisición de las referencias que debían nutrirlos. Si bien la evolución de los exámenes, siempre orales, debió más al antiguo régimen de estudios que a la innovación pedagógica liberal, la organización de "reuniones literarias", la creación de un "acta estatutaria" anual obligatoria, destinada a celebrar el 15 de septiembre y los héroes de la independencia, al igual que la implantación progresiva de sesiones solemnes

42 Bolaños, Discurso, 1850 , p. 5.

43 Staples, "Panorama", 1985. 
de distribución de premios, crearon condiciones de aprendizaje de la vida del foro, útiles a los futuros magistrados y hombres políticos que eran los alumnos, al mismo tiempo que permitieron incorporar a la galería de los modelos, los ejemplos de la ciudadanía del porvenir: buenos alumnos, héroes de la independencia, oradores sabios de las reuniones literarias. ${ }^{44}$

Así, en el Instituto se aprendía un arte oratorio republicano nutrido por los cursos de "Bellas Letras" que, a partir de 1845, fueron impartidos por el director de la institución (el canónigo Cantarines fue el iniciador de ese curso) durante los dos últimos años de los estudios de medicina y de derecho y a los cuales la asistencia era obligatoria. Pronto "licenciados" y "doctores", es decir los llamados a ocupar las más altas funciones de responsabilidad en el estado, los estudiantes del Instituto, pulían su instrucción mediante el estudio de los "principios generales de las bellas letras" (un curso diario por 6 meses), el de "historia general y particular de México" (un curso semanal por 6 meses), el del "análisis y la crítica

\footnotetext{
${ }^{44}$ Habida cuenta de la prestación poética del "joven Manuel C. Brioso", en ocasión de una distribución de premios en 1882, en el Períbdtco Oficial: "Para nosotros, Manuel representa al poeta práctico, es decir, al verdadero poeta. Nos hacen reír quienes buscan sus ideas en el cielo pero cuya vida está sumergida en el fango. Nos hacen el efecto de genios falsos. Pero cuando vemos un ser que, como Manuel, realiza el ideal, buen hijo, amigo espléndido, seguidor esiricto de todos sus deberes sociales, joven de conducta irreprochable, y, además, de ideas avanzadas, cuya imaginación fértil alimenta versos sonoros, entonces decimos: ¡He aquí el verdadero poeta!", Peribdico Oficial del Gobierno del Estado de Oaxaca, t.I, núm. 6, 21 de enero de 1882, p. 2.
}

de los clásicos antiguos y modernos" (id.) y en fin, mediante la práctica de "composiciones literarias sobre las materias de la profesión respectiva de los que cursan". 45 Mediante la práctica de los discursos cívicos y públicos del 15 de septiembre (aniversario de la Independencia), la historia nacional y sus héroes suplantaron progresivamente los ejemplos de la antigüedad clásica en las referencias de los oradores.

De este modo, tanto los profesores como sus mejores estudiantes serían durante todo el siglo, y hasta la revolu. ción, los autores de los "discursos cívicos" que marcarían el ritual político oaxaqueño y nacional y que proporcionarían, al lado de los periódicos, lo esencial de la producción impresa local. Además, en el último tercio del siglo que fue el de la estabilización política porfirista, el Instituto se convirtió en el centro de la vida cívica, mientras que las ceremonias religiosas, tan numerosas en la Oaxaca de la primera mitad del siglo, desaparecían del paisaje urbano debido a las leyes de reforma que prohibían las procesiones. El otorgamiento de premios, una de las ceremonias solemnes públicas del año, reunía, en torno al gobernador del estado, al personal y los alumnos del Ins. tituto, al conjunto de los notables de la ciudad. El Instituto monopolizaba la función simbólica mediante el dominio del discurso cívico, una de las formas más constantes de la pedagogía republicana. A cargo de la instrucción primaria del estado entre 1860 y 1891 ,

45 "Decreto que reforma el Instituto de Ciencias y Artes de esta capital. Reglamento", cap. XII, "De la Academia de Bella Literatura", en Hernández, Colección, pp. 418-433. 
esta institución promovía en todas las escuelas el mismo tipo de ceremonias. Los discursos que acompañaban esas celebraciones solemnes no dejarían de recordar a lo largo del siglo las ventajas de la instrucción para el progreso de la sociedad y la conservación de la paz pública: arte oratorio moralizador $y$ pedagógico, a menudo brillante, en ocasiones carente de efectos y austero hasta la banalidad como lo ilustraban los discursos de Juárez.

Si la renuncia a la cultura clásica puede explicar por sí misma la aparición de la retórica liberal moderna, también debe señalarse el papel desempeñado por las circunstancias políticas en la transformación de las referencias y de la estética del discurso. El final de los años de 1840, marcado por el desastre militar frente a los estadunidenses, la invasión del territorio y la sucesión de las "revoluciones", condujo a los liberales a considerar con pesimismo la experiencia de la "libertad" tan celebrada en los años de 1820 , y por consiguiente a adecuar su registro semántico conforme a esas horas lúgubres. En contraposición con las virtudes republicanas, aparecían los "vicios", "venganza, competencia por los empleos (aspirantismo), ambición", a los que se añadían las "divisiones", el "faccionalismo", el espíritu de partido y la falta de respeto a las leyes. Tales eran los males engendrados por los hombres "vicio. sos" que detenían a la sociedad en su camino hacia el progreso y la ilustración. ${ }^{46}$ Se trata de lugares comunes del discurso liberal de la época: los

46 Juárez, Exposict6n..., 1849. vicios de los individuos corrompían a la sociedad e impedian que se aplicasen las buenas leyes. ${ }^{47} \mathrm{~A}$ un político como Juárez, le era preciso designar a los culpables: los sediciosos, a quienes los ociosos y los vagabundos siempre estaban dispuestos a ayudar; a los militares indisciplinados que fomentaban "revoluciones" según su interés personal. Revolución:

Insurreccionarse contra la autoridad a viva fuerza, violando la paz y la seguridad de las familias [...] Los ciudadanos cuando tengan motivo de queja contra sus gobernantes, o crean algún acto injusto, deben representarlo a la autoridad superior para que ponga remedio; pero jamás lanzarse a una revolución, por los grandes males que causa a todo pueblo paralizando los giros, empobreciendo el país y armando al hermano contra el hermano, llevando el robo, el incendio y la muerte a todas partes y dejando la miseria, la desolación y las lágrimas. Todo hombre debe procurar que el orden y la paz se conserven siem. pre, pues a su sombra los pueblos se moralizan y progresan. 48

El constatar el fracaso de la "libertad", transformada en anarquía en los decenios que siguieron a la independencia, condujo a un antiguo liberal como Luis B. Santaella, profesor de filosofia del Instituto, a unirse al imperio de Maximiliano sin renunciar a ce-

47 Los sucesivos reglamentos del Instituto preven la expulsión o la no inscripción de alumnos considerados como "viciosos". La obediencia al reglamento y la asistencia al curso forman parte de los criterios de selección de los buenos alumnos, quienes serán recompensados en el momento de la distribución de los premios.

${ }^{48}$ Juárez, Catecismo, 1857, pp. 43-44. 


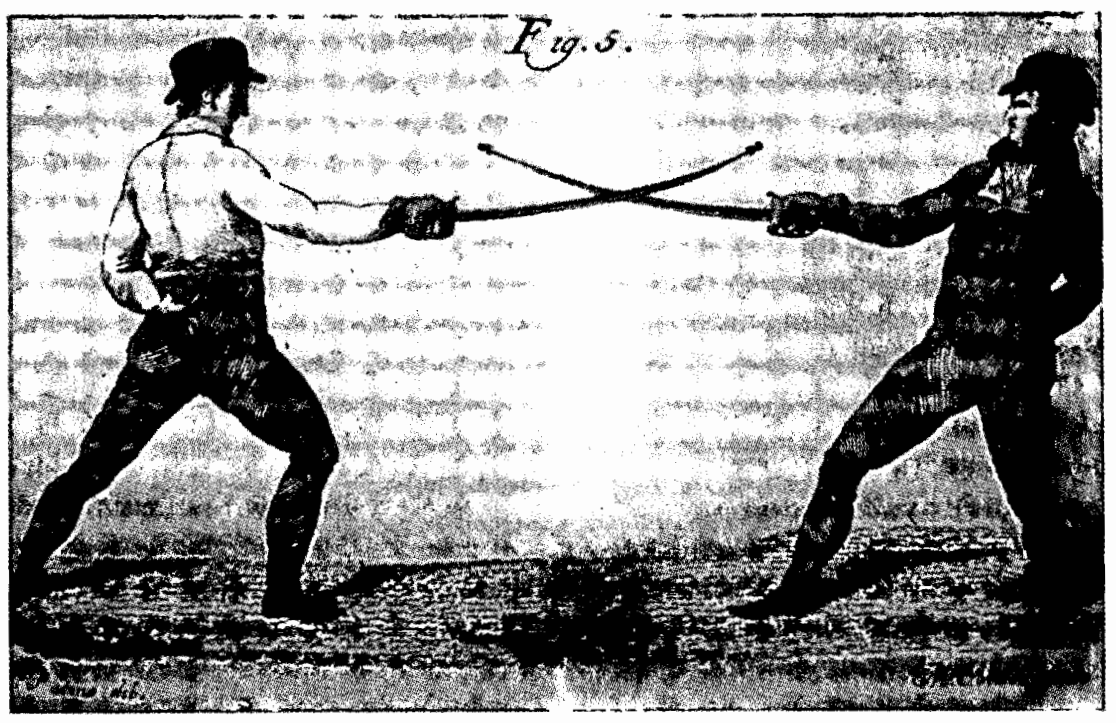

lebrar el rito fundador nacional, el aniversario de la independencia:

Cuando en un pueblo se llegan a desconocer las virtudes cívicas, cuando se entronizan en el poder las clases sin conocimiento ni instrucción [...], entonces no queda otro recurso para las repúblicas sino el entregarse en manos de príncipes que las dirijan y las salven [...] Los buenos hijos de México que no estaban contam inados con el cáncer que iba carcomiendo a los pueblos y que salvaron su conciencia y su honor en medio de nuestras guerras civiles $[\ldots]$ comprendieron que no habiendo en nosotros las virtudes para gobernarnos en un sistema republicano, sólo la institución monárquica podía salvarnos $[\ldots]^{49}$

${ }^{49}$ Santaella, Discurso, 1865, pp. 15-16.
Después de la victoria de 1867 sobre las fuerzas imperiales y el campo conservador, el triunfalismo estuvo de nuevo a la orden del día para celebrar la república reconquistada. Con la confirmación de la paz política en la década de 1880 , el discurso liberal consideraba con cierta resignación los años de anarquía como una etapa ciertamente deplorable pero inevitable en la marcha de México hacia el progreso. Las teorías evolucionistas comenzaban aquí a influir en la concepción liberal, poniendo menos énfasis en la conducta de la historia como buena gestión de la libertad y más en el cambio como fuerza histórica ciega. ${ }^{50}$ Esta modifica-

50 Véase Rabasa, Discurso, 1883. Emilio Rabasa (1856-1930), uno de los intelectuales más 
ción no impedía que se celebrasen siempre como parte esencial de la "herencia liberal", que en lo sucesivo se denominaría las "Luces":

¡Benditos mil veces los libros que como palancas omnipotentes elevan la conciencia hasta el derecho y al hombre hasta la apoteosis! Por eso Gutenberg merece también nuestra gratitud, cuando en los altares de la libertad americana incensamos a Guatimoc y a Xicoténcatl, a Hidalgo y a Guerrero, a Juárez, a Washington y a Bolivar.51

Era una forma de recordar la tradición civilista e ilustrada de los liberales oaxaqueños, siempre inclinados a celebrar más el saber que las proezas militares. Centro del culto que el estado oaxaqueño nunca dejó de dedicar a Juárez, el Instituto incluyó al héroe en su pedagogía: a principios del siglo $\mathrm{xx}$, al acercarse el primer centenario de su nacimiento, se invitó a los alumnos a participar cada año en un concurso de composiciones literarias, en verso y en prosa, que debían poner de relieve su acción histórica y sus méritos cívicos y personales. Incluso cuando el Instituto sufrió más claramente que antes la influencia del modelo educativo de la Escuela Nacional Preparatoria de México y reorganizó los estudios de acuerdo con una inspiración comtiana que ponía en primer plano las ciencias "positivas" (cfr. infra. "la expansión del Ins.

brillantes de la época porfirista realizó sus estu. dios de derecho en el Instituto y comenzó su carrera de magistrado en el estado de Oaxaca.

51 Atristain y Brioso, Discursos, 1883, p. 7 (el discurso citado es de Brioso, antiguo alumno y profesor del Instituto, magistrado). tituto"), el "cientificismo" no logró de ningún modo enfriar el entusiasmo de la elite oaxaqueña hacia los principios heredados del liberalismo local, mucho tiempo inspirado por la "Ilustración".

\section{LA EXPANSIÓN DEL INSTTTUTO, LAS GRANDES ETAPAS}

1826-1860. A pesar de, o tal vez debido a, sus primeras ambiciones, el Instituto conoció después de su creación un largo periodo de dificultades que se extendió hasta 1860. Las dificultades provenían de las peripecias de la agitada vida política de la época. Las "esca. seces del erario" relacionadas con las discontinuidades políticas y las guerras que marcaban la lucha entre las facciones fueron permanentes. El Instituto, feudo de los liberales, no siempre estaba en olor de santidad en opinión de las autoridades conservadoras que controlaban el poder local la ma. yor parte del tiempo. Los edificios, el sueldo de los profesores, la cantidad de clases abiertas sufrían las consecuencias de este ambiente poco favorable. Desde 1834, el Instituto se instaló en el antiguo convento de San Pedro y San Pablo, exiguo y mal adaptado a las funciones de la enseñanza. Los profesores, letrados, abogados o médicos ejercían, la mayor parte del tiempo, como voluntarios, y con frecuencia las clases se cerraban por falta de maestros o de alumnos.

En efecto, el reclutamiento de alumnos era irregular, y sobre todo, muy débil. En 1828 , no se contaban más que 26 inscritos (12 en gramática 
latina, 12 en derecho, 7 en lenguas). ${ }^{52}$ En 1831, mientras el Seminario contaba con más de 200 alumnos, el Instituto no atraía más que a una treintena, sin contar los 118 alumnos inscritos en el curso de dibujo. ${ }^{53}$ Sin embargo, en las dos décadas posteriores a su fundación, el Instituto vio aumentar la cantidad de sus alumnos y llenarse sus principales cursos. Un balance establecido para los años de 1845 y 1849 registra 98 alumnos en 1845 y 308 en 1849 , pero esas cifras extraídas del informe presentado por el gobernador Juárez deben considerarse con prudencia: se trataba de rivalizar con el Seminario, al que se reconocían en esa fecha más de 350 alumnos. ${ }^{54}$ Como siempre, la suma de los inscritos en los distintos cursos da una cifra muy superior a la cantidad real de alumnos. Sin embargo, según un testigo de la época,

este establecimiento científico que, a pesar de los recios golpes que la aristocracia, el despotismo y la brutal ignorancia le han dado continuamente, progresa [...] Cuando se mejore de él, y se atienda, cuando el espíritu de las luces le extienda, una mano protectora y encuentre un gobierno de verdadero civismo, fomentador y padre de las ciencias, entonces y sólo entonces se verán los sazonados frutos que deban producir esas aulas que serán el lustre de mi pa. tria querida $[\ldots]^{55}$

En 1852, el número de alumnos re.

52 Secretaría del Instituto, ms, 24 de septiem bre de 1828, AGEO, Gobernación: 1828.

${ }^{53}$ Exposición, 1831, doc. núm. 2.

54 Juárez, Exposictón, 1849, doc. núm. 12.

55 Carriedo, Estudios, 1949, vol. n, pp. 169170. almente inscritos no llegaba a los 130 . La mayoría de ellos seguían los cursos de las clases preparatorias, y los estudiantes de derecho o de medicina no superaban los quince.

Creado en un contexto federalista, el Instituto de Oaxaca se encontró expuesto al hostigamiento de la adminis. tración de México cuando los conservadores lograron imponer una constitución centralista: desaparecieron entonces las autoridades "soberanas" del estado, congreso y gobernador electo. Ése fue el caso entre 1835 y 1847 , salvo breves intervalos, y después, bajo la dictadura de Santa Anna, de 1852 a 1855. Durante ese periodo, el Instituto tuvo que cerrar sus cáte. dras de medicina, que la Universidad de México declaró no conformes con el curso reglamentario. ${ }^{56}$ El triunfo de la revolución de Ayutla y la llegada de los liberales al poder salvaron al Insti. tuto de ese mal momento, pero en 1859, durante la guerra de los Tres Años, la institución debió cerrar sus puertas cuando la ciudad cayó en manos del caudillo conservador Cobos; no habría más inscripciones durante todo el año de 1860.57

Sin embargo, esta primera etapa fue fecunda, sobre todo debido a la modernización de los estudios inscrita en la ley de 1845, que, inspirándose en la ley de Instrucción pública promulgada por el gobierno central en 1842 , rompió con las características de antiguo régimen de los programas anteriormente en vigor. A partir de enton-

56 "Sobre que se suspendan en Oaxaca los estudios de medicina", ms, 1855, AGN, Justicia e Instrucción Pública: vol. 87, ss. 248 a 261.

57 "Matrículas", 1858-1867, Arch. UABJO, n. c. 


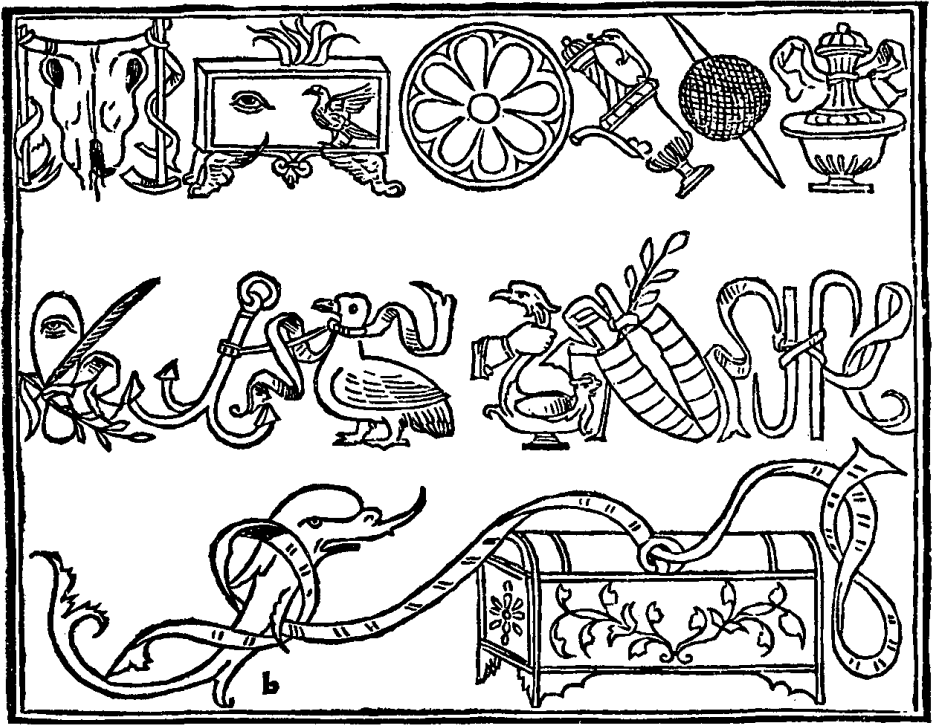

ces se distingue, por una parte, un ciclo de estudios secundarios llamados preparatorios, que duraban de 5 a 6 años, que proporcionaban una formación general y que se abordaban hacia la edad de 12 años; y, por otra parte, estaban los estudios superiores, llamados profesionales, de derecho, medicina y farmacia. 58

1869-1885. En 1860 comenzó para el Instituto un periodo de consolidación A pesar de las circunstancias, en particular la invasión extranjera (1862) y la tentativa imperial de Maximiliano, durante la cual, el estado fue ocupado portropas francesas (Oaxaca cayó en 1865), el Instituto permaneció

58 "Decreto que reforma el Instituto de Ciencias y Artes", Colección, 1987, vol. 1, pp. 418-433. constantemente en manos de personalidades liberales provenientes del círculo cercano a Juárez: Manuel Dublán (quien, aunque unido a Maximiliano, conservaba sus convicciones políticas) y luego Félix Romero y José Esperón fueron sucesivamente sus directo. res. Por fin el Instituto obtuvo los medios necesarios para su funcionamiento, gracias a las leyes de Reforma que consagraron la separación de la Iglesia y el Estado y decretaron la nacionalización de los bienes eclesiásticos. EI Instituto nuevamente recibió locales, que no fueron otros (ivaya símbolo!) que los del antiguo Seminario, así como una doble dotación en dinero extraída, a su vez, de la venta de los bienes nacionalizados, 100000 pesos del gobierno local y 200000 del go- 
bierno nacional (Benito Juárez era entonces presidente de la república en funciones). Asimismo el Instituto recibió el acervo de las bibliotecas de los conventos y del Seminario de Oaxaca. ${ }^{59}$

En esos años fue cuando el reclutamiento del Instituto, favorecido por el cierre obligado del Seminario, empezó a volverse consistente. No obstante, las cifras oficiales son poco creíbles. $\mathrm{Si}$ bien Manuel Dublán declaraba 359 ins critos el 3 de agosto de 1863, sólo aparecen 120 alumnos en el cuaderno de inscripciones. ${ }^{60} \mathrm{El}$ gobernador Félix Díaz (hermano de Porfirio) contaba 700 alumnos en 1870 , cifra que al menos hay que dividir entre tres para lograr una visión realista de las cosas. ${ }^{61}$ En efecto, en las listas de asistencia presentadas por los profesores en 1868 , no aparecían más que 277 alum. nos, de los cuales 53 estaban inscritos sólo en los cursos de dibujo, de música o de gimnasia. ${ }^{62}$ Pero, como quiera que sea, el Instituto en esa fecha con-

59 [Dublán], Memorta, 1863, p. 23.

60 "Matrículas", 1858 a 1867, Arch. UABjo, n. c.

${ }^{61}$ Díaz, Memoria, [1870], doc. núm. 63.

62 "1868" [listas de asistencia], Arch. UA вjo, n. c. Se plantea una pregunta: ¿Cómo explicar la presencia de inscritos tan numerosos en los cursos de música, dibujo y gimnástica, la mayoria en una o dos de esas únicas materias? Desde los inicios del Instituto, el curso de dibujo siempre atrajo gran cantidad de alumnos: este aprendizaje parecía estar considerado como útil para numerosos oficios manuales; la música, de la cual todas las fuentes hacen pensar que desde la época colonial hasta nuestros días es una de las artes más apreciadas de los oaxaqueños, muchos de los cuales la practican como aficionados en toda ocasión, constantemente formó parte de igual manera de las actividades del Instituto a partir de los años de 1860 . En cuanto a la gimnasia, ise concebía ésta como una preparación para los deberes militares? Las fuentes son mudas al respecto. solidó definitivamente su progreso. La reapertura de un colegio católico en $1871,{ }^{63}$ seguida pronto por la del Seminario, no llegó a amenazar seriamente la permanencia del Instituto.

1885-1910. La tercera etapa, que llamaremos "positivista" empezó con la promulgación en 1885 de una ley para reorganizar y modernizar el plan de estudios del Instituto. Esta gran ley se inspiraba en el plan de estudios que el ministro Gabino Barreda había elaborado en 1867 para la Escuela Nacional Preparatoria de México. El espíritu positivista se manifestaba sobre todo en la modificación del orden en el que se abordaban hasta entonces las materias del programa. En lo sucesivo se consagrarían los cuatro primeros años de estudios preparatorios a las matemáticas, a la física y a las ciencias naturales, así como a las lenguas extranjeras; el estudio de la gramática española no se abordaría sino hasta el quinto año, mientras que el sexto y último dejaría todo el lugar a las disciplinas no "científicas": literatura española y mexicana, historia nacional, instrucción cívica, lógica y psicología. Confirmando el lugar de los estudios profesionales clásicos (medicina y derecho), la ley de 1885 intentaba dar nueva vida a proyectos antiguos, organizando los estudios de farmacia, ingeniería, arquitectura, obstetricia, notaría, comercio y administración. ${ }^{64}$

Ese plan de estudios ambicioso ten-

${ }^{63}$ La Verdad. Perídico religioso de legisla. ción, ctentífico y literario, de la "Soctedad Ca. tólica", núm. 34, t. $\mathrm{l}$, domingo 8 de enero de 1871 , p. 4 .

64 "Plan de Estudios preparatorios y profesionales", Colección, vol. xI, 1887, pp. 386-399. 
dia a confirmar al Instituto en su papel de gran institución secundaria y universitaria capaz de cubrir la totalidad de las necesidades locales. Como se vería, cualesquiera que hayan sido los límites de esa ambición, la promulgación de la ley abrió un nuevo periodo de progreso que materializaba toda una serie de adquisiciones y de transformaciones del edificio. El Instituto construyó un observatorio meteorológico, adquirió numerosos instrumentos de física, se adaptó a la era pasteuriana dotándose de un gabinete bacteriológico y de microscopios. La adquisición de los instrumentos de experimentación, que confirieron prestigio al instituto y que le permitieron mantener una correspondencia científica constante con las instituciones de México, respondia a la doble preocupación de ponerse a tono con los últimos progresos de la "ciencia" y de renovar los métodos pedagógicos. "Acabamos -escribió el director Valdivieso en 1902de penetrar de lleno en la moderna civilización en la que debemos contar con fuerzas suficientes para no caer vencidos." Valdivieso propuso nuevos métodos de enseñanza, la renuncia al aprendizaje fundado en la memoria y en la palabra del maestro para

ejercitar a los alumnos en la observación y familiarizarlos con la experimentación, [...] No necesito encarecer cuán indispensable es un buen material de enseñanza para poder plantear estos métodos; en otros términos, es necesario contar con gabinetes, laboratorios y museos. 65

65 "Lista de honor de los alumnos que se distinguieron por su aplicación y constancia en los
La voluntad de progreso tan compenetrada con la cultura liberal local, asumió, bajo la influencia positivista y evolucionista, el ritmo de una carrera contra reloj. Se trataba de no quedarse atrás de las "naciones civilizadas" (europeas); el buen ciudadano no sólo se. ría un hombre libre y responsable, sino una mente adiestrada en la observación de las leyes de la naturaleza y de la sociedad.

Liceo, universidad y centro cientifico, el Instituto vio también en la misma época consolidado su papel de guardián de la memoria oaxaqueña y de templo del patriotismo local. A las buenas intenciones nunca concretadas en actos en los decenios anteriores, sucedió un plan de reacondicionamiento del museo de historia y de historia natural, ${ }^{66}$ que recibió nuevas colecciones. El catálogo de la biblioteca, que contaba con unos 15000 volúmenes, se terminó por fin en 1887.67 Como un símbolo más del espíritu del tiempo, en 1891 se emprendió la reparación completa del edificio del antiguo Seminario donde el Instituto siguió instalado y que no se consideraba ya adecuado a la estética moderna. Los motivos presentados para justificar esta costosa remodelación resumen bien el estado de ánimo de una elite local, que al mismo tiempo que era porfirista, era liberal y estaba deseosa de afirmar su identidad oaxaqueña: "Su frontispicio

estudios, durante el año de 1902 . Informe anual del Director." Memoria, 1903, pp. iii y x.

66 El Gabinete de Historia Natural y el Museo se crearon por el decreto del 22 de septiembre de 1832, y fueron confiados al Instituto. Expostctón, 1832, pp. 20-21.

67 Catálogo, 1887. 


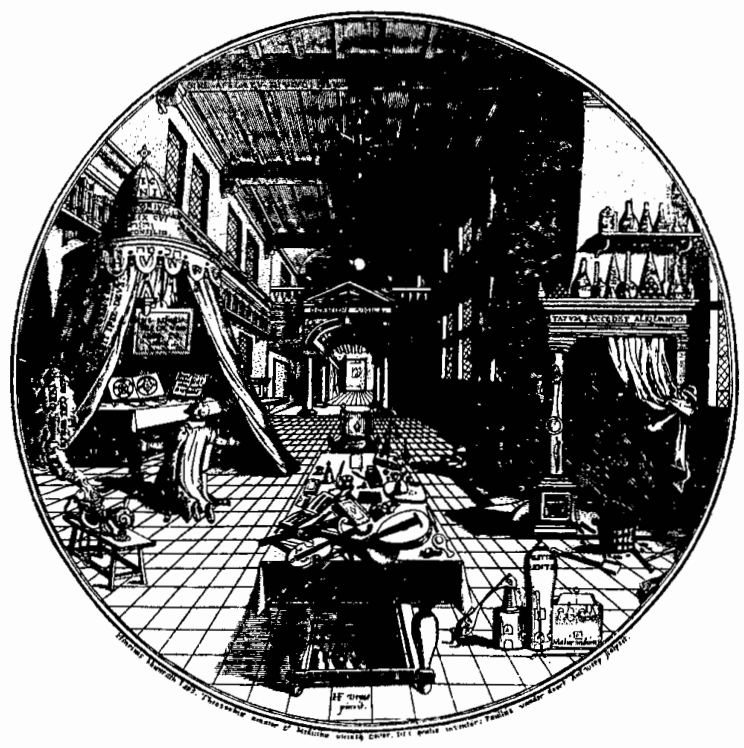

es de poco gusto arquitectónico y revela, además de su antigüedad, el estilo eclesiástico que se daba a los edificios pertenecientes al clero": el edificio no estaba a la altura de la "civilización" y del "buen gusto". Se encargó entonces $a$ un ingeniero que realizara

un proyecto de fachada, en el cual, sin sacrificar los preceptos de la ciencia, haga figurar en él la ornamentación zapoteca tomando como modelo la que comportan los antiguos palacios de $\mathrm{Mi}$ tla. 68

Al término de varios años de trabajo, el viejo seminario barroco tomó el

68 "Instrucción Pública", Memoria administrativa de 1891 , $\mathrm{ms}$, AGEO, n. C. aspecto de un edificio neoclásico decorado con frisos que recuerdan lejanamente el arte antiguo de los zapotecas.

La cantidad de alumnos inscritos siguió aumentando, favorecida por los nuevos cursos creados en 1885 , de comercio-administración y telegrafia. Otra etapa señaló la ley de 1898 , que organizó semestralmente los de secundaria, comercio y derecho. La innovación tenía por meta multiplicar las evaluaciones de los alumnos (exámenes semestrales) y favorecer el reclutamiento de más alumnos. Desde fines del siglo, las cifras oficiales, al menos las que emanaban directamente del Instituto, se vuelven más fiables y permiten medir el efecto de la reorganización de los cursos, como lo muestra la 
Tabla I. Número de alumnos inscritos en preparatoria, 1892-1902

$\begin{array}{cccc}1892^{\mathrm{a}} & 96 & \begin{array}{l}1898-1^{\mathrm{b}} \\ 1898-2\end{array} & 152 \\ & & 1899-1 & 105 \\ 1893 & 82 & 1899-2 & 142 \\ 1894 & & 1900-1 & 152 \\ & 93 & 1900-2 & 188 \\ 1895 & & 1901-1 & 157 \\ & & 1901-2 & 185 \\ 1896 & & 1902-1 & 166 \\ & & 1902-2 & 138 \\ 1897 & 94 & & 138 \\ & & & \end{array}$

2 1892-1897: ley de 1885 , preparatoria $=6$ años; inscripciones anuales.

Promedio de inscritos entre 1892 y $1897=92.5$

b 1898-1902: ley de 1898, preparatoria = 5 años; inscripciones semestrales.

Promedio de inscritos entre 1898 y $1902=154.7$.

"Lista de honor de los alumnos que se distinguieron por su aplicación y constancia en los estudios, durante el año de 1902. Informe anual del Director." Memoria, 1903, p. iv.

tabla I. Mientras que en 1895 la cantidad de inscritos en preparatoria era de 83 , aumentó en 1902 , tomando en cuenta la doble inscripción anual, a 300 (de los cuales, 10 eran mujeres, habiendo ingresado la primera de ellas al Instituto en 1896). La tabla II muestra por el contrario un efecto muy reducido de la organización en semes. tres sobre la asistencia al curso comercial ( 72 inscritos en $1897,{ }^{69}$ una media de 100 en 1900 , pero sólo 78 en 1902), al igual que sobre el de derecho (46 inscritos en 1897).

Otra evolución sensible a fines del siglo es que hubo mayor relación entre los cursos reales tomados por los alumnos y las exigencias dictadas por la ley.

${ }^{69}$ Informe, 1898.
Mientras que en los años de 1858-67, las trayectorias de los alumnos eran muy erráticas, y las inscripciones en los cursos parecen haberse realizado, en la mayoría de los casos, de manera relativamente arbitraria, ${ }^{70}$ el libro de inscripciones del año de 1896 testimonia por el contrario un gran rigor: de $\mathbf{4 6}$ alumnos inscritos en primer año del ciclo secundario, 31 seguían la totalidad de los cursos prescritos. ${ }^{71}$ Los cursos caprichosos tipo "antiguo régimen" se volvieron la excepción y ya no la regla; la racionalización positivista inscrita en la ley de 1885, al menos en ese campo, parece haber alcanzado su meta.

70 "Matrículas", 1858-1867, Arch. u^вјо, n. c. 71 "Libro de Matrículas. Año de 1896", Arch. UABJO, n.c. 
Tabla II. Número de alumnos inscritos en las carreras profesionales

$$
\text { Medicina } a^{\mathrm{a}} \text { Semestre Comercio Derecho }
$$

$\begin{array}{rrrrr}1897 & 19 & & & \\ 1898 & 19 & & - & 51 \\ 1899 & 20 & 1 & 102 & 36 \\ & & 2 & 120 & 32 \\ 1900 & 17 & 1 & 85 & 41 \\ & & 2 & 120 & 32 \\ 1901 & 20 & 1 & 98 & 26 \\ & & 2 & 76 & 33 \\ 1902 & 19 & 1 & 80 & 24\end{array}$

aLos estudios de medicina se llevaban a cabo en 6 años y los de derecho en 4 , después de haber cursado los 6 años de "preparatoria"; los de comercio en 3.5 años sin estudios preparatorios previos. Las inscripciones eran semestrales en derecho y en comercio. Ibid., pp. xviii-xix.

\section{OBSTÁCULOS Y BLOQUEOS}

\section{La imposible diversificación de las carreras}

¿Evolucionaron en el curso del siglo XIX las diversas carreras propuestas por el Instituto a sus alumnos? Como se ha visto, la fundación de esta institución pública correspondía a la necesidad de secularizar la enseñanza introduciendo en ella la de ciencias y humanidades y adaptarla a las necesidades de la administración pública. También se incluyeron entre las materias impartidas, el derecho canónico y la historia eclesiástica, pero desaparecerían definitivamente de los programas con la ley de 1845 , que ratificó la secularización de la formación según la lógica del proyecto de
1826. Éste, particularmente ambicioso, sufrió rápidamente diversas reducciones. Desde 1827 , apenas algunos meses después de la inauguración, el gobernador anunció el cierre de seis de las doce cátedras previstas, por no ser de "necesidad urgente": lenguas (inglés y francés, por considerarlas un "lujo"), cirugía, botánica, economía política e historia natural de México, derecho público constitucional y derecho de gentes (que se uniría a la cátedra de derecho civil y natural) ${ }^{72}$ Cons. tantemente se invocó la falta de alumnos y luego de medios, para explicar el cierre prolongado de numerosas cátedras.

En la época liberal, y después en la positivista, se afirmó claramente la in-

72 Morales, Memoria, 1827, p. 23. 
tención de las autoridades de diversificar las carreras propuestas. Según los legisladores y los directores del Instituto, no sólo se trataba de formar a los funcionarios públicos del Estado, es decir a los juristas, abogados, así como a algunos médicos destinados a encargarse de la salud pública, sino de producir una elite más numerosa, polivalente, útil al progreso de la economía y de la sociedad.

Sin embargo, aparece aquí un desfase no superado entre las intenciones y las realizaciones. Los ambiciosos proyectos que Manuel Dublán proponía en los años'de 1861.1863 o bien no fueron llevados a cabo o decayeron.

Los ramos que se enseñan -escribía en sus memorias de 1863- no corresponden todavía a las necesidades de Oaxaca [...] Es preciso abrir nuevas carreras a la juventud, no sólo en su beneficio sino precisamente en el del Estado. Hoy sólo se forman en el Instituto médicos, farmacéuticos y abogados; es ya necesario tener ingenieros de minas, topógrafos, agrimensores, agricultores científicos y profesores de las distintas ciencias que más aplicación tienen a las necesidades de la vida. Cuando el estado es esencialmente minero y agrícola, cuando tenemos tan malos caminos y cuando en la explotación de esos y otros muchos ramos en general no se tiene más guía que una rutina de cien años, la necesidad reclama la creación de otras carreras que sirvan para el desarrollo de la riqueza y para dar ocupación honesta y conveniente a la juventud. 73

Dublán proponía la creación de una

73 [Dublán], Memoria, 1863, p.15.
Escuela de Medicina dotada del más moderno material, de un Colegio de Minas y de Ciencias Físicas (donde se enseñaría especialmente la metalurgia), de un Colegio de Agricultura para promover, sobre todo, la ganadería. Como se ha visto, las dotaciones en material experimental no se recibirían antes del fin de siglo, y los Colegios de Agricultura y de Minas no alcanzarían a abrirse nunca. El proyecto de Escuela de Artes y Oficios, igualmente propuesto por Dublán, tuvo un inicio de realización y fue codificado en $\mathbf{1 8 7 0}$. Se trataba de:

10, ilustrar a la clase trabajadora del país, haciéndole mediante las ciencias auxiliares, más fácil y seguro su trabajo y mejores los resultados de él; $2^{\circ}$, aliviar a esta clase en su carrera, costeándole su enseñanza y dándole los métodos más seguros en la práctica de su arte; $3^{\circ}$, aplicar el trabajo a las primeras materias de que abunda el país, que no estén explotadas por los particulares $[\ldots] ; 4^{\circ}$, desarrollar las artes industriales $[. ..] ; 5^{\circ}$, servir de ejemplo a toda la clase trabaja dora, no sólo en el trabajo de las artes sino también en la moralidad, buena fe y puntualidad con que el hombre debe manejarse en sociedad. 74

Sin embargo, a fines del siglo, la escuela existente bajo el nombre de "Artes y oficios", más o menos asociada a la rehabilitación de delincuentes parecía vegetar.

Las nuevas carreras propuestas por el Instituto, en virtud de la ley de $\mathbf{1 8 8 5}$,

74 "Proyecto de reglamento interior de la Escuela Industrial de Artes y Oficios", F. Díaz, $\boldsymbol{M e}$. moria, [1870], doc. núm. 67. 
no conocieron mejor suerte que el proyecto de Manuel Dublán. Ingeniería y arquitectura desaparecieron en la ley de 1898. Al iniciarse el siglo, fuera de los cursos de derecho y de medicina sólo se profesaban los de obstetricia (seguidos por mujeres; de las 11 inscritas en 1903, sólo 8 seguían efectivamente los cursos), de notaría ( 7 inscritos en 1903), de comercio y administración (172 inscritos), así como el curso de telegrafia. La carrera de probador de metales (en dos años) no apareció sino a partir de 1902 y tenía poco éxito (13 inscritos en 1903, de los cuales sólo ocho asistían a los cursos) a pesar del desarrollo de la actividad minera en el Estado en ese periodo. Las nuevas carreras que tuvieron cierto éxito, como la de comercio-administración, eran las que ofrecían las salidas tradicionales en el comercio y en los empleos de oficina.

El aumento del número de alumnos al correr el siglo, que afectaba sobre todo el ciclo secundario, no correspondió sino a una diversificación muy limitada de las formaciones propuestas. Mientras el estado de Oaxaca, siguiendo la evolución económica del resto de México, experimentaba un pequeño auge agrícola y minero entre 1895 y 1907 (favorecido por la apertura de dos vías de ferrocarril y por la llegada de capitales extranjeros, ${ }^{75}$ el Instituto no logró unirse a esa corriente formando ingenieros, metalúrgicos o agrónomos. ¿Fue por falta de medios, o por falta de una verdadera voluntad política? ¿Fue por falta de alumnos, es decir de demanda social? Las carreras tradicionales en Derecho y Medicina abiertas en

75 Chassen, "Precursores", 1985, pp. 35-87.
1826 y cuyos diplomas seguían dando acceso a las más altas funciones administrativas y políticas, continuaban dominando, por su prestigio más que por la cantidad de alumnos. En 1904, el gobierno que había gastado 33000 pesos para el Instituto, pensionó además a 13 estudiantes enviados a México para realizar estudios de derecho o de medicina y para seguir los cursos de la Escuela de Artes y Oficios, ${ }^{76}$ con lo cual, parecía renunciar al antiguo sue. ño de contribuir al "progreso" de Oaxaca y ratificar el peso creciente de la ciudad de México y el proceso de centralismo porfirista. Pero se pueden sugerir otras dos razones: por una parte, una situación de bloqueo escolar global de la que el bloqueo del Instituto era tan sólo el resultado; por otra parte, la domesticación, en el seno del sistema porfirista, de una elite liberal convertida en oligarquía provinciana, que lograba gracias al Instituto, reproducir sus valores y sus posiciones y perpetuarse a la cabeza de las instituciones del Esta do, e incluso acceder a cargos federales que brindaban prestigio, aunque no poder, al establecer un vínculo personal con Porfirio Díaz. ¿No se convirtió el Instituto en el objeto de una oligarquía local renuente o incapaz de aban donar a otros los privilegios de una educación elitista?

\section{POBLACIÓN ESCOLAR Y PRODUCCIÓN DE TITULADOS}

Al terminar el siglo, el triunfalismo siempre a la orden del día a propósito

76 Pimentel, Memoria, 1904, p. 50. 


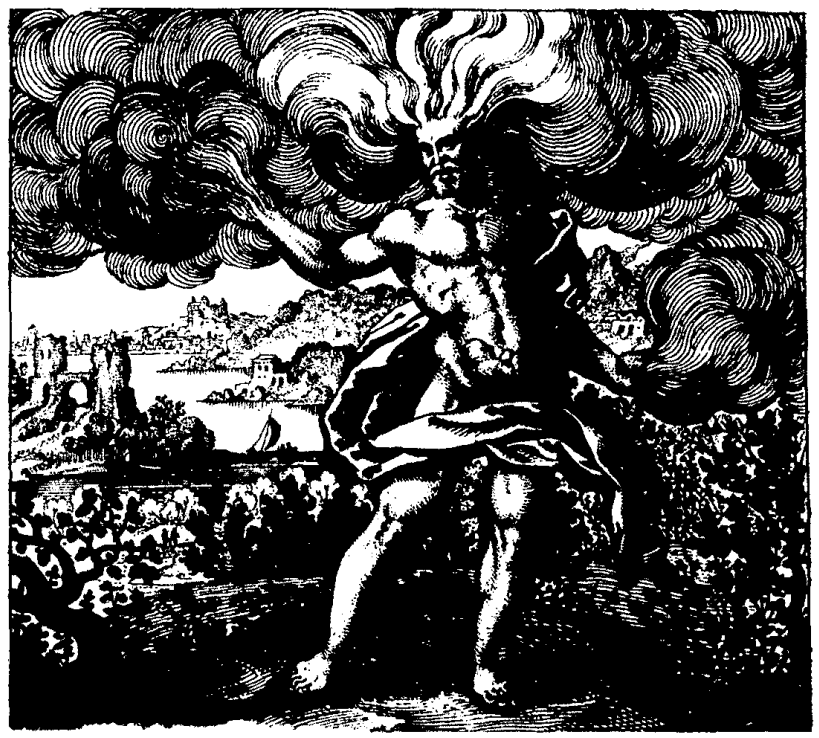

del Instituto, se vuelve más crítico, es decir más reticente. El médico Valdivieso, director científico del Instituto, en un esfuerzo inaudito de esclarecimien. to y de honestidad, apuntaba en sus balances anuales las cantidades reales de alumnos inscritos y de los aprobados en los exámenes. El licenciado Emilio Pimentel, electo gobernador del estado en 1902, compañero de banca de Valdivieso en el Instituto 25 años antes, ${ }^{77}$ mostraba la misma preocupación en sus informes ante el Congreso local. Mientras el Instituto a partir de enton. ces fue financiado regular y casi com-

77 "Matrículas", 1858-1867, Arch. UAвJo, n. c. pletamente como la escuela primaria por las finanzas públicas, para las autoridades llegó la hora de sacar cuentas y de evaluar la rentabilidad del conjunto del sistema.

Como se ha visto, la cantidad de alumnos del Instituto aumentó de manera irregular pero constante en el transcurso del siglo XIX. Sin embargo, se constata que la cantidad de titulados no aumentó y, más aún, que las deserciones a lo largo del año, que no son perceptibles al reportar sólo el total de inscritos, vienen a ser la principal característica de la población escolar de la institución. Así, el centenar de alumnos inscritos en preparatoria en 1896 se repartía de la siguiente manera: 
Tabla III. Alumnos de preparatoria, 1986

$\begin{array}{ccc}\text { Nivel } & \text { Inscritos } & \begin{array}{c}\text { Total } \\ \text { decursos }\end{array} \\ \text { I } & 46 & 31 \\ \text { II } & 22 & 9 \\ \text { III } & 10 & 6 \\ \text { IV } & 11 & 9 \\ \text { V } & 11 & 9 \\ \text { VI } & 3 & 1\end{array}$

a A lumnos inscritos en todas las materias del programa.

El primer año de preparatoria, el que seguía inmediatamente a la escuela primaria, aparece como sumamente selectivo $(-50 \%)$ y el alumnado se estabilizaba en tercer año; sólo subsistían los alumnos muy buenos, aquellos que podian seguir la totalidad de las materias del programa. La pérdida en el curso de primer año es igual, en el curso más corto, que en los programas me- nos cargados, de comercio-administración, al igual que en el curso de telegrafía (de dos años). Ahora bien, son precisamente esas carreras, las que como el primer año de preparatoria, incrementaron el alumnado global del Instituto a fines de siglo. Las inscripciones semestrales aplicadas en 1898 no modificaron profundamente la situación: la cantidad de alumnos que se presentó a los exámenes fue siempre inferior de 30 a $50 \%$ a la cantidad de inscritos, fueran las que fuesen las carreras. En derecho y medicina, la cantidad de alumnos que aprobaban los exámenes era siempre ínfima en relación con el número de inscritos, e incluso la proporción de los que aprobaban los exámenes en relación con la cantidad de candidatos era siempre muy elevada. La selección por lo tanto se realizaba antes, en el transcurso del año.

En esas condiciones, la cantidad de titulados que egresaban cada año del Instituto parece irrisoria:

Tabla IV. Número de alumnos que terminan sus estudios $1897-1902^{\mathrm{a}}$

$\begin{array}{ccccc} & \text { Medicina } & \text { Semestre } & \text { Comercio } & \text { Derecho } \\ 1897 & 4 & & & \\ 1898 & 0 & & & \\ 1899 & 1 & 1 & & 0 \\ & 2 & 0 & 0 & 3 \\ 1900 & 3 & 1 & 3 & 0 \\ & & 2 & 8 & 4 \\ 1901 & 4 & 1 & 3 & 2 \\ & & 2 & 0 & 5 \\ \text { a "Lista de honor...", Memoria, 1903, pp. xvm.xix. } & 1 & 5 & 0 \\ & & \end{array}$


Paradójicamente, el curso comercial, que proponía una formación profesional corta, casi producía los mismos titulados que los largos estudios prestigiosos de medicina y derecho. En cuanto a estos últimos, la situación no es nueva, puesto que la cantidad de diplomados de fin de estudios coincidía con la que se había dado a lo largo de todo el siglo XIx. La cantidad de abogados diplomados en Oaxaca entre 1829 y 1861 aumentó a 100 , es decir una media de 3.6 por año, ${ }^{78}$ mayor que el promedio de los aprobados entre 1897 y 1902 . Los resultados fueron los mismos por lo que concierne a los diplomados de medicina: de 1834 a 1861, 23 personas recibieron el título de médico, es decir, apenas 1 por año en promedio; de 1862 a 1903 , se contaron 38 titulados, una media anual idéntica. ${ }^{79}$

Ni el crecimiento demográfico, ni el progreso económico, ni la estabilidad política pudieron modificar esta situación estructural. Los títulos de licenciado y de doctor siguieron siendo privativos de una pequeña elite muy restringida, aquella que monopolizaba las altas funciones públicas y los cargos políticos. En el último año de la carrera de medicina, no era raro ver a un único alumno inscrito: hijo de alguna notabilidad cuyos estudios eran fi-

78 "Noticia de los abogados oaxaqueños con expresión de las fechas en que se despacharon y de su residencia en 1 de julio de 1861", Cajiga, Memorta, 1861, doc. núm. 47.

79 "Médicos cirujanos recibidos en la escuela de medicina de Oaxaca..." Nuestro Tiempo (número especial de homenaje al hospital general Aurelio Valdivieso), Revista de la Universidad "Benito Juárez" de Oaxaca, núm. 2, mayo-agosto 1957, pp. 23.25 . nanciados onerosamente por el presupuesto público. ${ }^{80}$ Mientras que incluso desde el punto de vista de los métodos didácticos, la ambición de los programas, la seriedad del seguimiento y la tutoria de los alumnos, el Instituto experimentó su apogeo a fines de siglo y, al parecer, produjo tantos fracasos como excelencia.

Sin duda puede deducirse de esos resultados, que los estudios secundarios en el Instituto no constituían un factor de promoción social significativo en el estado de Oaxaca. Sin embargo, unas conclusiones apresuradas en este campo pueden conducir a un contrasentido, en primer lugar, porque la democratización de la enseñanza secundaria y de la superior mediante ella, nunca formó parte de los objetivos de las autoridades políticas y escolares. Su intención fue siempre la de formar la elite necesaria para el funcionamiento de las instituciones; y el fracaso de las carreras profesionales orientadas hacia la actividad económica no fue pues el fra. caso de una voluntad de democratización; además, porque el acceso al primer año de preparatoria, incluso cuando lo seguía una deserción, constituía en sí mismo una promo. ción con respecto al conjunto de la población escolar del Estado. En efecto, una gran mayoría de alumnos era eliminada de la escuela desde el ciclo de los estudios primarios. La inscripción en el Instituto no fue maltusiana de manera sistemática, y las

${ }^{80}$ Es el caso en 1896 , donde el único inscrito es un Mimiaga, descendiente de una de las gran. des familias de terratenientes del estado. 
causas de su limitación deben buscarse río arriba.

Aureliano Valdivieso fue también quien proporcionó, por primera vez, cifras que hablan por sí mismas (tabla v).

Aunque el distrito del centro, el más urbanizado del estado, reunía las condiciones favorables para una escolarización regular, la deserción era considerable: apenas el $2 \%$ de los alumnos de primaria (que estaban lejos de representar la totalidad de la población en edad escolar) llegaban al final de los estudios elementales, menos del $1 \%$ acababa la primaria superior. Los demás distritos del estado, mucho más rurales, no contribuían más que sim. bólicamente a la cantidad de alumnos inscritos en el Instituto, que aparece así como el coto de la elite urbana de la capital del estado.

La incoherencia de las cifras presentadas en la época del gobernador Martín González a propósito de la escuela primaria traduce el estancamiento en que se encontraban las autoridades del estado, indecisas entre el voluntarismo y el realismo. Las cifras máximas

Tabla v. Alumnos de primaria/alumnos inscritos en preparatoria (1898-1902)

$$
\begin{array}{lllll}
1898 & 1899 & 1990 & 1901 & 1902
\end{array}
$$

$\begin{array}{crrrrr}\begin{array}{c}\text { Alumno de primaria } \\ \text { (Distrito Centro)* }\end{array} & 7484 & 6528 & 4889 & 7631 & 6193 \\ \begin{array}{c}\text { Tramitaron primaria } \\ \text { elemental (Centro) }\end{array} & 145 & 141 & 171 & 166 & 163 \\ \begin{array}{c}\text { Tramitaron primaria } \\ \text { superior(Centro)** }\end{array} & 67 & 63 & 68 & 73 & 68\end{array}$

\section{Ingresaron a preparatoria}

Distrito del Centro
Distritos del Norte
Distritos del Sur
Distritos del Este
Distritos del Oeste
Otros estados

$\begin{array}{rrrrr}42 & 55 & 48 & 52 & 49 \\ 0 & 1 & 0 & 1 & 1 \\ 2 & 2 & 4 & 1 & 1 \\ 3 & 3 & 5 & 3 & 6 \\ 4 & 5 & 10 & 5 & 6 \\ 7 & 3 & 5 & 4 & 3\end{array}$

"El Distrito del Centro, que comprende la ciudad de Oaxaca y las aldeas circundantes, es el más urbanizado del estado.

* Ia escuela primaria llamada superior comprendía seis años (de los 7 a los 12 años) y concluía con un examen cuya aprobación era obligatoria para poder inscribirse en el Instituto. La mayoría de las escuelas primarias del estado eran "elementales" (o sea, 3 años de estudio). 
corresponden a los periodos de interés de los jefes políticos (encargados de la administración y de la policía de los distritos) quienes multiplicaban las presiones sobre los padres de familia para que inscribiesen a sus hijos en la escuela. La cantidad de inscritos volvía a disminuir en cuanto cesaba la presión. En su informe de 1904, Emilio Pimentel rompió con el triunfalismo de su predecesor, al retener la cantidad de 20493 varones y 4962 niñas presentes en las escuelas... ¡lo que bajó a la población escolar del estado a la situación de 1870! Mientras el estado consagraba en promedio 250000 pesos anuales a las escuelas primarias, suma que distaba mucho de ser insig. nificante en esa época, 125000 niños no estaban escolarizados:

que llegarán a ser otros tantos analfabetas en lo futuro, si no se procura impartirles la instrucción conveniente. La disminución del alfabetismo en nuestro estado es uno de los problemas más dificiles de resolver en la actualidad a causa de la escasez de recursos del gobierno, pues para impartir la instrucción obligatoria a tan considerable número de niños, sería preciso invertir anualmente, sólo en sueldos de maestros, la respetable suma de 500 mil pesos aproxima. damente. ${ }^{81}$

No se puede pues invocar la indiferencia de las autoridades frente al problema escolar para explicar el bloqueo del conjunto del sistema, sino las causas del estancamiento. Habría que buscarlas -aquí no es el lugar- en la concepción misma de la escuela primaria.

81 Pimentel, Memoria, 1904, pp. 55-56.
En vista de los programas y de la organización conjunta de los estudios, la escuela aparece como inadaptada a las necesidades y a las expectativas de una población rural e indígena mayoritaria que se resiste a esta escolarización exógena. Es probable que los objetivos pedagógicos y el nivel de exigencia hayan parecido inaccesibles, y sobre todo inútiles, a la mayoría de la población (Pimentel confiesa una tasa de analfabetismo del $85 \%$ ), mientras que el contenido mismo de la enseñanza -laica, científica, individualista- seguía siendo ajena para una población campesina con un modo de vida comunitario y muy marcada por lo religioso. ${ }^{82}$

Tabla VI. Alumnos (1895-1902)

$\begin{array}{rrc} & \text { Primaria } & \text { Preparatoria } \\ 1895 & 51892 & 83 \\ 1896 & 54355 & 93 \\ 1897 & 58699 & 106 \\ 1898 & 97847 & 255 \\ 1899 & 66622 & 392 \\ 1900 & 44486 & 499 \\ 1901 & 90554 & 490 \\ 1902 & 61345 & 419\end{array}$

a Establecido a partir de "Instrucción Pública", Memoria administrativa, 1902 (gobernador Martín González), doc. núm. 4 y 6.

82 Sobre el asunto de la educación de los indigenas concebido por los cientificistas, véase A. Lempérière, "Sobre", en prensa. 
${ }^{9}$ El Instituto no era pues un factor de movilidad social, porque la escuela primaria misma no cumplía ese papel. El estancamiento del sistema remite a la fragmentación cultural y social que caracterizaba al estado de Oaxaca, donde el crecimiento económico, demasiado tímido hacia finales del siglo, no logró romper el aislamiento del campo movilizando a la población rural, ni dar consistencia a las capas sociales intermedias, de ordinario, las más demandantes en materia de educación. La elite liberal, incluso impreg. nada de realismo científico, no pudo hacer nada para promover de hecho a la sociedad de ciudadanos ilustrados cuyo ideal perseguía el Instituto desde la Independencia.

\section{PARENTELA Y PATROCINIOS}

Entre la Reforma y la Revolución, el Instituto parece haber tenido como principal función la de instruir y reproducir socialmente las parentelas asociadas al movimiento liberal de mediados de siglo. Aún más, se autoalimentaba: todos sus directores, a partir del final de 1840 , salieron de sus filas. En $1897,30 \%$ de los 32 profesores de la institución habían sido alumnos en ella entre 1859 y 1867 , al igual que su secretario, Carlos Cerqueda. En la medida en que 29 del total de ellos eran "licenciados" o "doctores", resulta que cerca de $100 \%$ hizo en realidad sus estudios en el Instituto, y éste no recibía como alumnos más que a los procedentes del interior de las fronteras del estado.

Se puede ir más lejos al comparar las listas de inscritos de los años de 1859 . 67 y 1896. De los 176 apellidos de la lista, $57 \%$ (98) se encontraba ya en las listas de 1859-1867. Los apellidos que con mayor frecuencia se repitieron, en esos años, remitían todos a familias de la facción liberal. En medio de una multitud de alumnos oscuros, de los cuales muchos se inscribirían sólo una vez en una única materia, los hijos y los sobrinos de militares (los Ballesteros, los Díaz Ordaz, los Mejía...), de grandes propietarios (los Mimiaga, los Fagoaga), y aquellos miembros de profesiones liberales (los Bolaños, Sandoval, Santaella, etc...) descollaban en cantidad y logros en las clases del Instituto. Entre esas numerosas progenituras, uno o dos individuos destacaron por la regularidad y extensión de sus estudios, y la presencia del invasor francés entre 1865 y 1867 no modificaría en nada esta situación. Los descendientes de estas mismas familias se encuentran en las listas de fines de siglo. En esta fecha, la renovación de los patronímicos se explica por el aumento de los inscritos. Entre los que se titularon en derecho y medicina, los patronímicos se dividen poco más o menos de igual manera, entre "viejos" y "nue$\operatorname{vos}^{n}$.

La carencia de documentos relativos al origen social del conjunto de alumnos y de profesores no permite ir más allá en la historia social del Instituto, sobre todo, en el análisis de los fenóme. nos eventuales de movilidad social. Por el contrario, lo que resalta con claridad es la producción por el Instituto del pequeño grupo de titulados que se encontraba a la cabeza del estado, como gobernadores -cuando estos últimos 
no eran militares- secretarios de gobierno, diputados locales, magistrados, personal del Instituto, etcétera.

De cualquier modo, es probable que la historia social y la historia politica tengan que mezclarse estrechamente en el análisis de la movilidad social. ¿Cómo distinguir en efecto lo que depende del "grupo", o de la "cla-

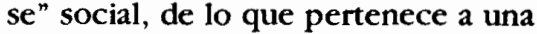
realidad "faccional", en una sociedad donde las relaciones de clientela, comenzando por las que vinculaban a Porfirio Díaz con los oaxaqueños, ${ }^{83}$ eran tan dominantes? Los escasos ejemplos hermosos de promoción social notable que conocemos, comenzando por los de Juárez y Díaz mismos, dependieron del más puro patronazgo, un fenómeno totalmente usual en la época colonial. ${ }^{84} \mathrm{~A}$ finales de la intervención francesa, la protección de que se benefició Rosendo Pineda por parte de Díaz es ejemplar, pero no única. Hijo ilegítimo de una indígena zapoteca de Juchitán y de un viajero francés, Rosendo Pineda, al igual que su hermano Apolonio, fue elegido por Porfirio Díaz, cuyas tropas estaban acantonadas en la aldea, para ser enviado al Instituto, mientras que un tercer niño de Juchitán fue designado para ser instruido en el arte militar. Rosendo Pineda realizaría todos sus estudios en el Instituto en compañía de Valdivieso y Pimentel, sus contemporáneos y de su generación. Una vez licencia-

83 Para el análisis de las estructuras y de las relaciones de poder en la época porfirista, véase Guerra, Mexique, 1985.

84 Véase Juárez, Apuntes, 1976, y Diaz, Me. moria, [1870]. do, realizaría una brillante carrera intelectual y política como miembro del grupo de los científicos, en el marco de una fidelidad absoluta a Díaz. Este último lo nombró, como a otros, diputado, pero no consintió jamás en dejarlo regresar a hacer carrera en su estado natal, contrariamente a Pimentel. ${ }^{85} \mathrm{La}$ correspondencia de Juárez testimonia también que el patronazgo escolar era un buen medio para los líderes políticos, para reclutar y conservar a sus fieles. Promoción de talentos, en efecto, pero cuando ésta se une a una sólida protección política $o$ a un origen familiar favorable, parece ser una paradoja para esta institución surgida de la llustración y del liberalismo.

\section{CONCLUSIÓN}

La voluntad de modernización que animó a las elites oaxaqueñas desde la Independencia y que siempre inspiró su política escolar, ya fuera en el Instituto o en la escuela primaria, no logró penetrar en la sociedad. La frontera no estaba abierta para una cultura liberal que promovía el individualismo, la racionalidad, la ciencia, la laicidad en una sociedad que se regía por los valores sociales tradicionales. A este respecto, el Instituto de Ciencias y de Artes aparecía, sobre todo en su periodo positivista, a un mismo tiempo como el brillante triunfo del voluntarismo de la Ilustración y como su fracaso. En la medida en que la escuela primaria misma quedaba fuera del alcance de

85 Véase Brioso y Candiani, Vida, 1938. 
la mayoría de la población del estado, el Instituto, foco de los valores del liberalismo y de la modernidad, estaba destinado a convertirse en un medio cerrado cuya ambición y éxito en la formación de una elite educada y cultivada no tuvo verdadera repercusión en el conjunto del cuerpo social. Al inicio del siglo $\mathrm{XX}$, el pesimismo de los dirigentes porfiristas y positivistas, con Valdivieso en el Instituto y Pimentel en el gobierno, confrontados a esos obstáculos, fue el síntoma del fin de una época. Las guerras civiles revolucionarias, conducidas y ganadas por los hombres del norte, significarían para los oaxaqueños el fin del acceso al poder nacional. El siglo Xx fue para esta elite venida a menos, el siglo de la amargura y de las consideraciones nostálgicas sobre la pérdida de las "tradiciones", y el declive de la ciudad y del Instituto.

\section{BIBLIOGRAFIA}

-Atristain, Joaquín, y Manuel C. Brioso, Discursos pronunciados por los CC. Licdos..., oradores nombrados por la Junta Patriotica del Centro, para ocupar la tribuna popular en los días 15 y 16 de setiembre de 1883, Imprenta del Estado, Oaxaca, 1883.

-Berry, C., La Reforma en Oaxaca. Una microhistoria de la revolución liberal 1856-1876, Ediciones Era, México, 1988 (ed. en inglés, 1981).

- "Ficción y realidad de la Reforma", en Lecturas, 1990, vol. III.

-Bolaños, Juan Nepomuceno, Discurso que en la solemne función de lectura de calificaciones $y$ distribucion de premios, entre los alumnos del Instituto de Ciencias y Artes del estado de Oaxaca, pro- nunció el director del establecimiento $y$ catedrático de fisiología $D . . .$, la noche del día 1 de enero de 1851 , impreso por Ignacio Rincón, Oaxaca, 1850 (B.N., México, R 708 LAF).

-Brioso y Candiani, M., Vida y significación del Lic. Rosendo Pineda, Mérida, 1938.

- La evolución del pueblo oaxaqueño desde la Independencia hasta el plan de Ayutla. 1821 a 1855 (Ensayo de historia cientifica), Tacubaya, 1941.

-Buchanan, E., El Instituto de Toluca bajo el signo del positivismo (1870. 1910), Universidad Autónoma del Estado de México, 1981.

-Cajiga, Ramón, Memoria que el C. Ramón Cajiga gobernador constitucional del estado de Oaxaca presenta al segundo Congreso de Oaxaca, 16 de septiembre de 1861, Imprenta Ignacio Rincón, Oaxaca, 1861

-Canseco, J.J., Explicación ulterior sobre los inconvenientes que obstan al establecimiento de la libertad de cultos en la Republica Mexicana, impreso por Ignacio Rincón, Oaxaca, 1849.

-Carbajal, Bernardino, Discurso que en la solemne función de la bendición de la bandera del Batallon Ligero Guerrero, guardia nacional de esta ciudad, pronunció en el templo de la Purísima Con. cepción el día 28 de diciembre de 1847 el Presbítero $C$..., impreso por Ignacio Rincón, Oaxaca, 1848.

-Carriedo, J.B., Estudios historicos y estadísticos del estado oaxaqueño, 2 vols, Biblioteca de autores de asuntos oaxaqueños, México, 1949.

-Castrejón Diez, J., y M. Pérez Lizaur, Historia de las universidades estatales, Secretaría de Educación Pública, México, 1976.

- Catálogo alfabético de la Biblioteca del Estado, Imprenta del Estado, Oaxaca, 1887,270 pp.

-Chassen, N., "Los precursores de la revolución en Oaxaca", La Revolución en 
Oaxaca, 1900-1930, Instituto de Administración Pública de Oaxaca, 1985.

- Colección de Leyes y Decretos del Estado de Oaxaca, s. e., 1887.

-Costeloe, M., La primera república federal de México (1824-1835). Un estudio de los partidos políticos en el México independiente, Fondo de Cultura Económica, México, 1975.

-Díaz, Félix, Memoria que presenta el Ejecutivo del Estado... el 16 de setiembre del presente año [1870], Tipografia del Estado, Oaxaca, 1871.

-Díaz, Porfirio, Memorias, elede, México, 1947.

-[Dublán, Manuel], Memoria que sobre Instrucción Pública presenta el director del Instituto... al gobierno del estado, Tipografia del Instituto, Oaxaca, 1863.

-El Instituto de Ciencias y Artes del Estado. Los años de formación (antología de documentos), UA BJO, Oaxaca, 1990.

-Exposición que el tercer gobernador del estado hizo... el 2 de julio de 1832, Imprenta del Supremo Gobierno, Oaxaca, 1832.

-Exposición que el vicegobernador... hizo... el 2 de julio de 831, Imprenta del Supremo Gobierno del Estado, Oaxaca, 1831.

-Galíndez, José Mariano, Discurso filosófico-religioso que en la solemne acción de gracias, por la conclusión del curso de artes del señor canónigo doctor D.J.M. Álvarezy Castillejos, protonotario apostólico y catedrático de filosofía en el Seminario, pronunció en el templo de Nuestra Señora de la Soledad, el día 15 de julio, el Sr. magistral doctor $D$... catedrático de prima de sagrada teología del mismo seminario, oficina de Antonio Valdés y Moya, Oaxaca, 1846.

-García González, F., Francisco García Salinas y su obra educativa, Universidad Autónoma de Zacatecas, Cuadernos de Investigación, núm. 51, s/f, mecanografiado. , Conciencia e inteligencia en Zacatecas. Sociedad, educación, historia
(1550-1890), Universidad Autónoma de Zacatecas, Zacatecas, 1988.

-García Luna Ortega, M., El Instituto Literario de Toluca, Universidad Autónoma del Estado de México, 1986.

-Guerra, Francois Xavier, Le Mexique de l'Ancien Régime a la Revolution, 2 vols., L. Harmattan, 1985 [México: del an. tiguo régimen a la Revolución, Fondo de Cultura Económica, México, 1988.]

-Hamnett, Bajan R., Política y comercio en el sur de México, 1751-1821, Instituto Mexicano de Comercio Exterior, México, 1976.

-, "El comercio de la grana y la actividad de los alcaldes mayores", en Lecturas,vol. II, Epoca colonial, 1990, pp. 345-366.

-Herrejón Peredo, Carlos, Fundación del Instituto Literario del Estado de México [en Toluca], México, 1978.

-Informe anual rendido por el Direc. tor del Instituto..., Oaxaca, 1898.

-Iturribarría, J.F., La generación oaxaqueña del 67. Sintesis biográfica, Publicaciones de la UABJO, Oaxaca, $\mathbf{s} / \mathrm{f}$.

,José Maria Díaz Ordaz. Breves apuntes biográficos, Secretaría de Educación Pública, México, 1967.

-Juárez, Benito, Exposición que... hace el gobernador... el 2 de julio de 1849, impreso por Ignacio Rincón, Oaxaca, 1849.

, Apuntes para mis hijos, Secretaría de Educación Pública, México, 1976.

, Exposición que el gobernador del estado hace... el día 2 de julio de 1852 , impreso por Ignacio Rincón, Oaxaca, 1852.

Catecismo político dedicado a la instrucción primaria de la juventud oaxaqueña. Corregido y aumentado nuevamente por su autor, impreso por Ignacio Rincón, Oaxaca, 1857.

, Documentos, discursos y correspondencia, 15 vols, selección y notas de Jorge Tamayo, Libros de México, México, 1972. 
-Lecturas históricas del estado de Oaxaca, Instituto Nacional de A ntropología e Historia, México, 1990.

-Lempérière, Annick, "Sobre el pueblo de la Reforma a la nación revolucionaria", en De los imperios a las naciones, en prensa.

-Martínez Gracida, M., "Reseña histórica. El Instituto. Vida de Juárez", original mecanografiado, sin paginación [inicios del siglo $\mathrm{XX}$ ].

, Efemérides oaxaqueñas, 1853-1892, 2 vols., El Siglo XIX, México, 1892.

-Martínez Reding, F. (coord.), Historia de Jalisco, 4 vols., Gobierno del Estado de Jalisco, 1981.

-Mateos, Juan M., Historia de la masonería en México desde 1806 hasta 1884 , México, 1884

-Memoria del Instituto de Ciencias y Artes del estado de Oaxaca, Imprenta del Fstado, Oaxaca, 1903.

-Monaghan, J., "La desamortización de la propiedad comunal en la Mixteca", en Lecturas, 1992, vol. III, pp. 343-386.

-Morales, Memoria que el gobernador del estado de Oaxaca presentó en la apertura de las sesiones ordinarias del segundo Congreso Constitucional del mismo, verificado el 2 de julio de 1827, Imprenta del gobierno, Oaxaca, 1827.

-Muñoz y Pérez, D., D. Ignacio Mejía, brazo armado de la ley, Secretaría de Educación Pública, México, 1966.

-Pardo, R., Breve estudio sobre la evolución del Instituto de Ciencias y Artes del estado de Oaxaca., Imprenta del Estado, Oaxaca, 1926.

-Pimentel, Emilio, Memoria administrativa Presentada por el C. Lic..., gobernador constitucional del estado de Oaxaca, a la XXII legislatura del mismo, el 17 de septiembre de 1904, Imprenta del Estado, Oaxaca, 1904.

-Rabasa, Emilio, Discurso pronunciado por el C. Lic..., orador nombrado porla
Junta Patriotica para la solemnidad del 5 de mayo de 1883, Imprenta del Estado, Oaxaca, 1883.

-Ramírez, A. F., Hombres notables y monumentos coloniales, s.e. 1948.

-Representación que los ciudadanos oaxaqueños que suscriben dirigen al Congreso Nacional Mexicano, por conducto del Excmo. Sr. presidente de la Republica, a efecto de que no se destruya la constitución del año de 1824, haciendo tariación de la forma de gobierno; ni aun se reforme sino por las vias legales, México, 1835.

-Ruz Menéndez, R., Historia del Instituto Literario de Yucatán (1867-1922), Mérida, Universidad Autónoma de Yucatán, 1989.

-Santaella, Luis B., Discurso pronunciado en la noche del día 15 de septiembre de 1865, en el portal del Palacio de la Prefectura Superior Politica del Departa. mento, por el licenciado D..., impreso por Manuel Rincón, Oaxaca, 1865.

-Silva y Escobar, E., Instituto de Ciencias y Artes del Estado. Monografia en ocasión del CXXVAniversario de su Fun-. dación, 1827-1952, s. e., Oaxaca, 1952.

-Staples, A., "Panorama educativo", en Ensayos sobre historia de la educación en México, El Colegio de México, México, 1985 , pp. $127-144$.

, Educar: Panacea del México independiente, El Caballito/Secretaría de Educación Pública, México, 1985 (antología de textos sobre la educación por los ideólogos mexicanos del siglo XIX).

Taylor, W.B., Landlord and peasant in colonial Oaxaca, Stanford University Press, 1972.

, Historia de la cuestión agraria mexicana. Estado de Oaxaca, vol I, Prehispánico-1924, Juan Pablos, México, 1988.

Velasco, A.L., Geografía y Estadística de la República Mexicana, vol. Ix, Oaxaca de Juárez, 1891. 